\title{
Tecnología lítica en el Auriñaciense arcaico de Cueva Morín (Villanueva de Villaescusa, Cantabria)
}

\author{
José Manuel Maíllo Fernández ${ }^{\dagger}$
}

\begin{abstract}
In the last years, the characteristics of beginning of Upper Palaeolithic in the Cantabrian region has suffered a very important renovation since the classification of Bernaldo de Quirós. The identification of new industrial's group and the El Castillo's dates have promoted this "revolution".
\end{abstract}

Cueva Morin is located in the region of Cantabria, $9 \mathrm{~km}$ to the south of the city of Santander. This cave, known since the

beginning of past century, presents a statigrafical sequence spanning from the Mousterian to the Azilian in 22 archaeological levels.

The study of the lithics of levels 9 and 8 (Archaic Aurignacian) have allowed the know the lithic technology of this period in the Cantabrian region. These levels provide relevant bladelet production linked

to two different schema opératoire: prismatical core and carinated endscraper. The bladelets characteristics are the right profile and no torsion. The bladelets productions is mainly oriented to the performance of Dufour bladelet.

\section{RESUMEN}

En los últimos años, las caracteristicas de los inicios del Paleolítico superior en la región cantábrica han sufrido una importante renovación desde la clasificación propuesta por Bernaldo de Quirós. La identificación de nuevos grupos industriales y las dataciones de la cueva de El Castillo han promovido esta "revolución".

Cueva Morín se localiza en la comunidad autónoma de Cantabria, a nueve kilómetros al sur de la ciudad de Santander. Esta cueva, conocida desde los inicios del pasado siglo, presenta una secuencia estratigráfica que abarca desde el Musteriense hasta el Aziliense en 22 niveles arqueológicos.

El estudio de la colección lítica de los niveles 9 y 8 (Auriñaciense arcaico) nos permite conocer la tecnología lítica de este periodo en la región. Estos niveles revelan una producción de hojas/hojitas ligados a dos esquemas operativos diferentes: núcleos prismáticos y raspadores carenados. Las caracteristicas de las hojitas son regularidad y ausencia de

' Profesor Ayudante. Dpto. de Prehistoria y Arqueología, UNED, Madrid. E-mail: jlmaillo@geo.uned.es 
The blades are less important in this levels, but there are a continuum between

the blade and bladelet production.

In other hand, we must rebound the importance of the flakes production in the retouch flakes than the unretouch flakes.

The flakes production is linked to an unique schéma operatoire: discoid. The flakes production is mainly oriented to the performance of sidescraper, denticulates and encoches.

KEY WORDS

Archaic Aurignacian, Cueva Morín, Lithic Technology torsión y se orientan a la confección de hojitas Dufour.

Las hojas son menos importantes en el conjunto, aunque existe un continuum entre la producción de hojas y de hojitas.

Por otro lado, debemos resaltar la importancia de las lascas en la producción de soportes retocados, asi como entre los soportes brutos. La producción de lascas está ligada con un único esquema operativo: discoide. La producción de lascas se orienta a la ejecución de raederas, denticulados y muescas.

PALABRAS CLAVE

Auriñaciense Arcaico, Cueva Morín, Tecnologia Lítica

\section{INTRODUCCIÓN}

El inicio del Paleolítico Superior en la región cantábrica presenta innovaciones interesantes desde los últimos veinte años. A partir de un Musteriense final se desarrolian dos grupos industriales que podemos denominar "transicionales": el Chatelperroniense y el Auriñaciense de Transición. A partir de aquí encontramos un Auriñaciense arcaico bien definido.

Pese a este panorama tan revelador, el Auriñaciense ha sido el gran olvidado en los estudios paleolíticos de la región cantábrica. Es por ello, por lo que en este trabajo pretendemos revitalizar este tecnocomplejo desde un punto de vista tecnológico y ubicarlo en su marco regional.

\section{CUEVA MORIN}

Situada en Villanueva de Villaescusa, cueva Morín es conocida también como Mazo Moril o cueva del Rey. Está situada en una pequeña colina de formación urgoniana en la cuenca de drenaje del Solía, a sesenta metros sobre el nivel del mar y a seis kilómetros de la línea actual de costa (Fig. 1). La entrada de la cavidad está orientada hacia el noroeste, se prolonga a continuación en dirección sureste para terminar en dirección suroeste (González Echegaray \& Freeman, 1971).

La cueva fue descubierta para la Prehistoria por $\mathrm{H}$. Obermaier y $\mathrm{P}$. Wernet en 1910. Dos años más tarde, en 1912, J. Carballo y P. Sierra realizan un pequeño sondeo que queda inédito. $O$. Cendrero publicará más tarde algunos de los materiales extraídos del área de excavación de estos investigadores (Cendrero, 1915). Entre 1917 y 1919, J. Carballo retoma los trabajos en la cueva y realizará la que podemos considerar como la primera intervención seria en el yacimiento. Durante esta 

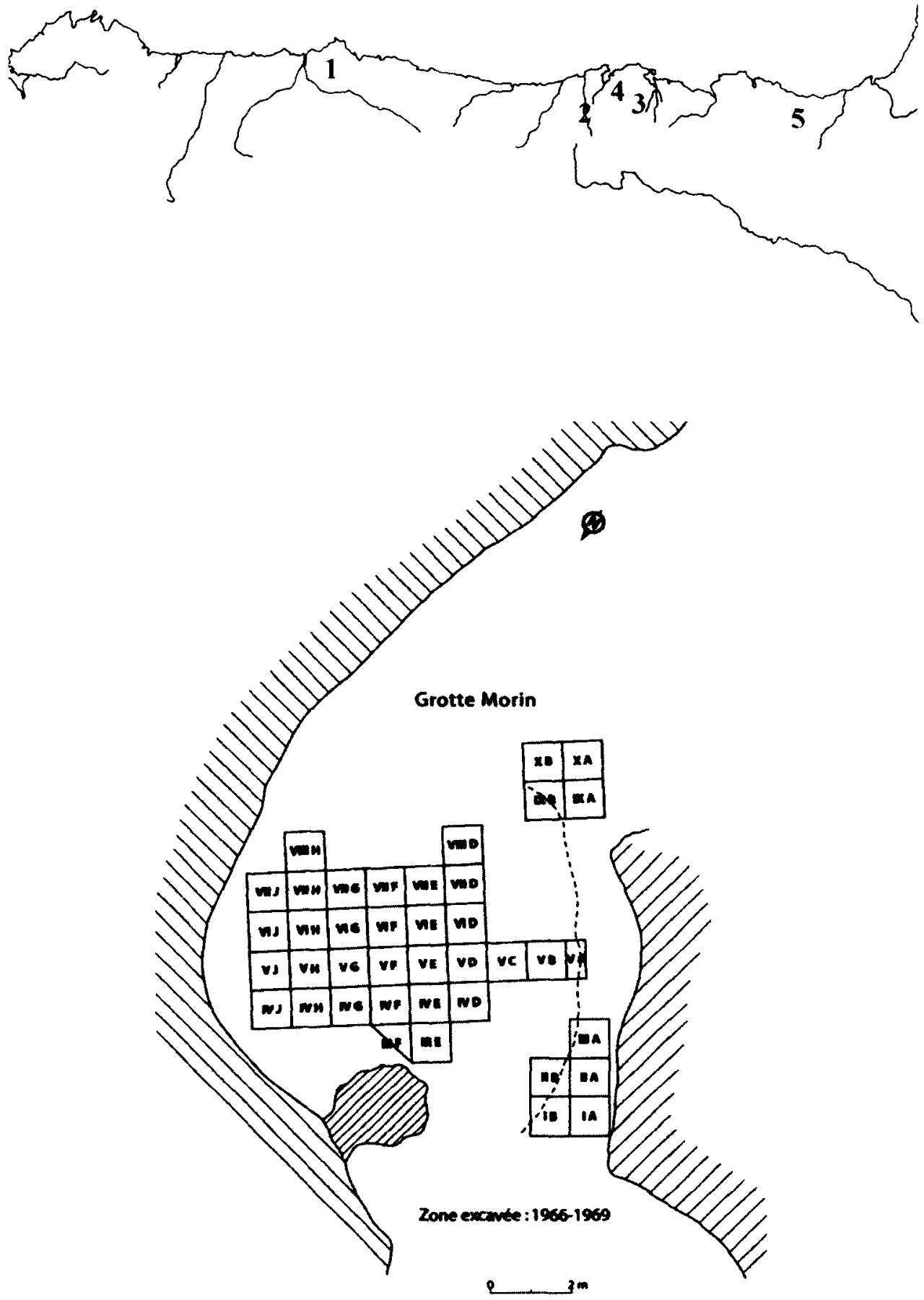

Fig. 1. Mapa de localización de los yacimientos cantábricos citados en el texto y plano de Cueva Morín. 
intervención se excavan los niveles correspondientes al Paleolítico superior y dos niveles del Paleolítico medio (Carballo, 1923). En 1918, al término de la primera campaña, J. Carballo invita al Conde de la Vega del Sella a excavar el yacimiento tras la finalización de las campañas del primero. Estas nuevas intervenciones en cueva Morín son rápidamente dadas a conocer a la comunidad científica (Vega del Sella, 1921). Hasta 1966 no se retoman los trabajos en este yacimiento, trabajos que durarán hasta 1969. Lo llevan a cabo un equipo hispano-americano dirigido por el Prof. J. González Echegaray y L. G. Freeman (González Echegaray \& Freeman, $1971 ; 1973 ; 1978)$. Esta intervención aportó a la Prehistoria española dos aspectos de vital importancia. Por un lado, la aplicación de métodos de excavación modernos $y$, por otro lado, la primera secuencia completa entre el Paleolítico medio y el superior en nuestro país. Esta secuencia estratigráfica revelaría la presencia de un nivel Chatelperroniense y, por tanto, la solución al debate en torno al auriñaco-musteriense (González Echegaray, 1969, Moure Romanillo, 1969-70).

La secuencia estratigráfica que presenta el yacimiento se compone de $22 \mathrm{ni}$ veles, cuyas atribuciones industriales son las siguientes: nivel 1: Aziliense; nivel 2: Magdaleniense; nivel 3: Solutrense superior; nivel 4 y 5b: Gravetiense; nivel 5a: Auriñaciense evolucionado; niveles 6 y 7: Auriñaciense antiguo; niveles 8 y 9: Auriñaciense arcaico; nivel 10: Chatelperroniense; niveles 11 a 17: Musteriense; niveles 18 a 21: Estériles y nivel 22: Musteriense.

\section{EL AURIÑACIENSE ARCAICO: Niveles 9 y 8}

\subsection{Sedimentología}

El nivel 8 forma un misma unidad estratigráfica con el subyacente nivel 9 . Sedimentológicamente, corresponde a limos arcillosos de color marrón rojizo. Contiene de forma dispersa gravas alteradas. Está formado por materiales finos transportados por agua de baja energía y de régimen laminar, ocasionalmente difuso y sin canalización (Laville \& Hoyos, 1994).

\subsection{Restos faunísticos}

Los restos de fauna son muy escasos. Para el nivel 8 se componen de solamente 22 restos que corresponden a un NMI de 2 individuos para Equus caballus y de un solo individuo para Capreolus capreolus, Cervus elaphus y Sus scrofa. En el nivel 9 existen 4 restos. Corresponden a un solo individuo de Bovidae y Equus caballus (Altuna, 1971).

\subsection{Industria ósea}

El nivel 9 presenta un fragmento distal de azagaya, la cual se encuentra muy deteriorada (González Echegaray, 1971). No existen más piezas de industria ósea o elementos de adorno o simbólicos en el nivel 8. 


\subsection{Industria lítica: aspectos generales}

El nivel 8 presenta una gran riqueza de materiales tanto a nivel cuantitativo como cualitativo. Presenta casi 3100 productos de débitage y 9462 desechos de talla. Los productos de débitage se dividen en 1010 lascas, 690 hojas y 1023 hojitas.

El nivel 9 es menos rico en material lítico. Está compuesto por más de 1300 productos de débitage y más de 3000 restos de talla. Los productos de débitage se componen de 791 lascas, 178 hojas y 167 hojitas.

Los grupos auriñaciense han empleado una gran panoplia de materias primas, entre las que se encuentran la cuarcita, la arenisca, la ofita, el cristal de roca, el oligisto, el cuarzo o la limonita. Sin embargo, la materia prima más representada es el sílex: $85 \%$ en el nivel 8 y $57 \%$ en el 9 .

El silex es también la materia prima más empleada para la realización de hojas y de hojitas. El débitage de lascas es realizado sobre un mayor número de materias primas. Estas producciones son efectuadas bajo una concepción discoide. Todas las etapas de la cadena operativa se encuentran representadas en el yacimiento.

Los soportes retocados lo forman 234 piezas en el nivel 9 y 581 en el nivel 8 (cuadro 1). En el nivel 9 son más numerosas las piezas de sustrato (raederas, denticulados, esquirlados y muescas) con un $44 \%$. Le siguen en importancia las piezas con retoque continuo (19\%). En el nivel 8 ocurre a la inversa, las piezas con retoque lateral son las más numerosas $(25 \%)$ seguidas de las piezas de sustrato $(24,7 \%)$. El grupo de las hojitas retocadas es fuerte en el nivel $9(7 \%)$ y muy importante en el nivel $8(20,3 \%)$.

\section{EL DÉBITAGE LAMINAR}

Los métodos de producción de hojas son estudiados y conocidos gracias a numerosos trabajos en diversos yacimientos a partir de núcleos de morfología prismática (por ejemplo, Ortega, 1998; Bon, 1998; Klaric, 1998, Chiotti, 1999, Bordes, 2002). Los recientes trabajos dedicados a la producción hojitas en el Auriñaciense proponen tres esquemas a partir de los cuales se obtienen dichos soportes. Estos son los núcleos carenados, los buriles y los núcleos prismáticos (Schmider y Perpère, 1995; Lucas, 1997, 1999, 2000, 2001; Soriano, 1998; Chiotti, 1999, 2000; Bon, 1998, 2000; Chazan, 2001; Bordes \& Lenoble, 2002). En la industria del Auriñaciense arcaico de Cueva Morin, la morfología y las características tecnológicas de los soportes y de los propios núcleos nos permiten proponer la existencia de dos esquemas operativos para la producción laminar. 
Cuadro 1. Lista tipológica de los niveles 9 y 8 (Auriñaciense arcaico) de Cueva Morin (según Maillo Fernández, 2003)

\begin{tabular}{|c|c|c|c|c|}
\hline & \multicolumn{2}{|c|}{ NIVEL 8} & \multicolumn{2}{|c|}{ NIVEL 9} \\
\hline & $N .^{\circ}$ & $\%$ & $N .^{\circ}$ & $\%$ \\
\hline 1. Raspador simple & 6 & 1 & 1 & 0,43 \\
\hline 2. Raspador atípico & 10 & 1.7 & 2 & 0,85 \\
\hline 3. Raspador doble & 2 & 0.4 & & \\
\hline 4. Raspador ojival & 3 & 0,5 & 2 & 0,85 \\
\hline 5. Raspador sobre hoja o lasca retocada & 11 & 1,9 & 6 & 2,56 \\
\hline 6. Raspador sobre hoja auriñaciense & 2 & 0.4 & 1 & 0,43 \\
\hline 7. Raspador en abanico & 2 & 0.4 & & \\
\hline 8. Raspador sobre lasca & 5 & 0.9 & & \\
\hline 9. Raspador circular & 2 & 0.4 & & \\
\hline 11. Raspador carenado & 23 & 4 & 2 & 0,85 \\
\hline 12. Raspador carenado atípico & 9 & 1,5 & 2 & 0,85 \\
\hline 13. Raspador espeso en hocico & 7 & 1,2 & 4 & 1,7 \\
\hline 14. Raspador plano en hocico $u$ hombrera & 7 & 1,2 & 2 & 0,85 \\
\hline 15. Raspador nucleiforme & 6 & 1 & 1 & 0,43 \\
\hline 16. Rabot & 1 & 0.2 & & \\
\hline 17. Raspador-buril & 2 & 0.4 & 1 & 0,43 \\
\hline 23. Perforador & 9 & 1.5 & 6 & 2,56 \\
\hline 24. Perforador atípico & & & 1 & 0,43 \\
\hline 25. Perforador múltiple & & & 1 & 0,43 \\
\hline 26. Microperforador & 1 & 0.2 & & \\
\hline 27. Buril diedro recto & 5 & 0.9 & 1 & 0,43 \\
\hline 28. Buril diedro desviado & 1 & 0.2 & & \\
\hline 29. Buril diedro en ángulo & & & 1 & 0,43 \\
\hline 30. Buril sobre fractura & 15 & 2.6 & 3 & 1,28 \\
\hline 34. Buril sobre truncatura recta & 6 & 1 & & \\
\hline 35. Buril sobre truncatura oblicua & 3 & 0.5 & & \\
\hline 36. Buril sobre truncatura cóncava & 1 & 0.2 & & \\
\hline 46. Punta de Chatelperrón & & & 2 & 0,85 \\
\hline 47. Punta de Chatelperrón atípica & 5 & 0.9 & 2 & 0,85 \\
\hline 58. Hoja de borde abatido total & 2 & 0.4 & 5 & 2,13 \\
\hline 59. Hoja de borde abatido parcial & 1 & 0.2 & 2 & 0,85 \\
\hline 60. Truncatura recta & 1 & 0.2 & 2 & 0,85 \\
\hline 61. Truncatura oblicua & & & 3 & 1,28 \\
\hline 63. Truncatura convexa & 1 & 0.2 & & \\
\hline 65. Pieza con retoque continuo sobre un borde & 123 & 21.2 & 38 & 16,23 \\
\hline 66. Pieza con retoque continuo sobre dos bordes & 21 & 3.6 & 6 & 2,56 \\
\hline 67. Hoja auriñaciense & 7 & 1.2 & 4 & 1,7 \\
\hline 74. Muesca & 32 & 5.5 & 10 & 4,27 \\
\hline 75. Denticulado & 32 & 5.5 & 23 & 9,82 \\
\hline 76. Pieza esquirlada & 13 & 2.2 & 9 & 3,84 \\
\hline 77. Raedera & 67 & 11.5 & 61 & 26,06 \\
\hline 78. Raclette & 2 & 0.4 & 1 & 0,43 \\
\hline 84. Hojita truncada & 2 & 0.4 & & \\
\hline 85. Hojita de dorso & 3 & 0.5 & 1 & 0,43 \\
\hline 87. Hojita de dorso denticulada & 1 & 0.2 & & \\
\hline 89. Hojita con muesca & 5 & 0.9 & & \\
\hline 90. Hojita Dufour & 104 & 17.9 & 15 & 6,41 \\
\hline 92. Diverso & 15 & 2.6 & 12 & 5,12 \\
\hline Total & 581 & 100 & 234 & 99,9 \\
\hline
\end{tabular}




\subsection{Esquema I: los núcleos prismáticos}

Disponemos de 37 ejemplares de este tipo de núcleos en el nivel 8 y de 15 para el 9 . Están realizados a partir de pequeños nódulos o sobre lasca y, en menor medida, sobre tectoclasto o plaqueta. Obsenvamos cómo existe una reducción paulatina en los soportes obtenidos entre hojas y hojitas a partir de un continuum en el proceso de reducción (gráfico 1 y gráfico 2).

Gráfico 1. Relación anchura-espesor entre los soportes laminares del nivel 8.

$$
\text { Ancho Hojas-Hojitas ( } n=1695)
$$

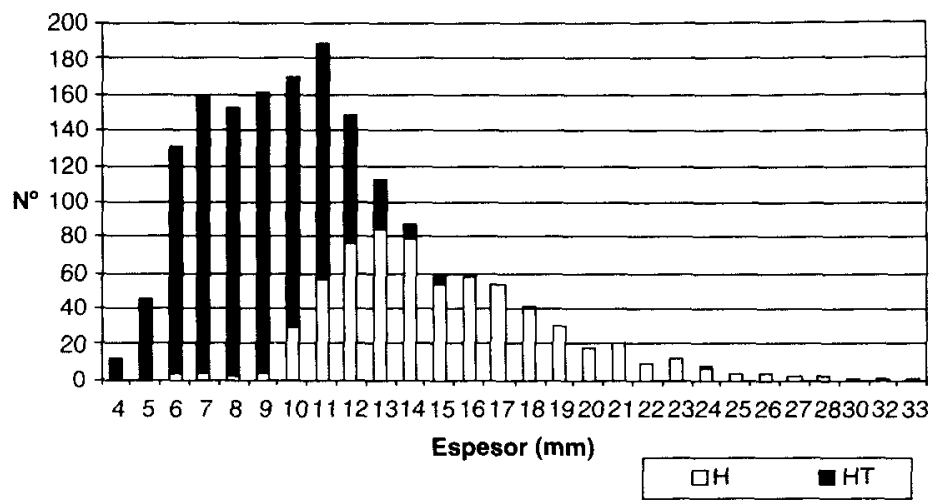

Gráfico 2. Relación anchura-espesor entre los soportes laminares del nivel 9.

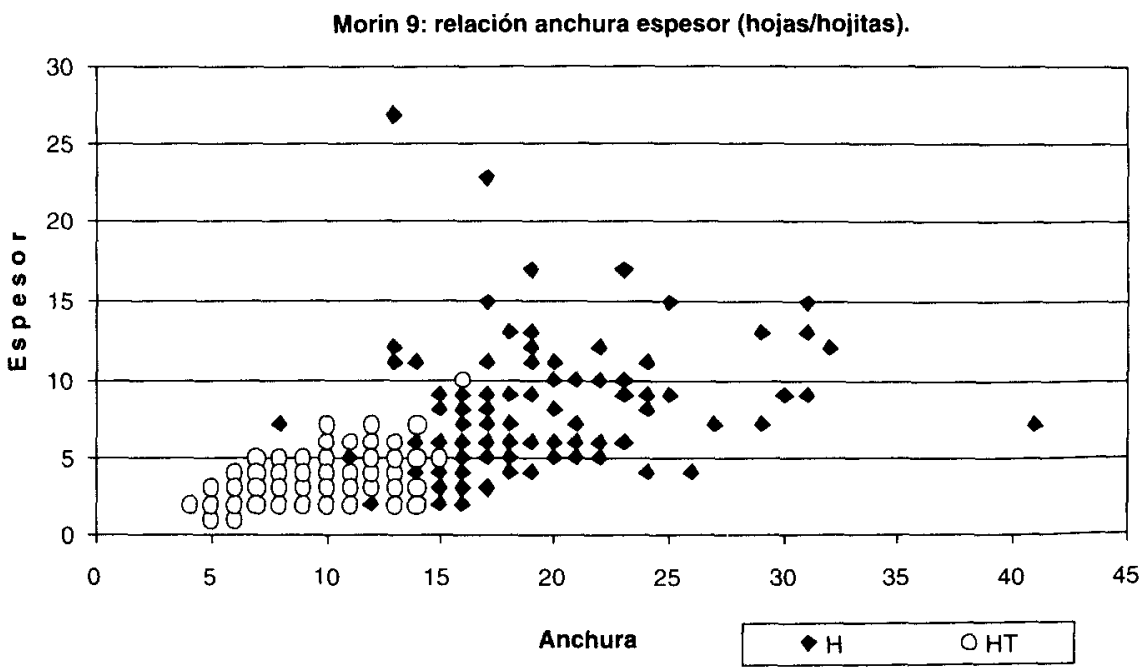




\section{- Fase de mise en forme}

La mise en forme es aparentemente sencilla. El inicio del débitage se corresponde con hojas de entame. Existe una adecuación morfométrica previa del soporte empleado, por lo que no existe cresta, excepto cuando el volumen inicial es cúbico ya que en estos casos sí se desarrollan algunas crestas laterales, aunque no de forma sistemática (Fig. 2). A partir de esta hoja de entame, la tabla se desarrolla en dirección a los dos flancos gracias a la extracción de lascas laminares. Este hecho podría explicar el escaso número de hojas corticales o semicorticales que existen en la colección. Las tablas presentan numerosas morfologías, sobre todo rectangulares o cuadradas, con una cierta tendencia a la convergencia distal.

El plano de percusión se prepara mediante la extracción de una tableta de núcleo que crea una superficie lisa y ligeramente cóncava. Esta superficie es también reavivada en el transcurso del débitage a raíz de los numerosos negativos observados en los planos de percusión de los núcleos. Éstos no se llevan a cabo cuando el soporte empleado para el núcleo prismático es una gran lasca. En estos casos, la cara bulbar realiza la función de plano de percusión y no se reaviva jamás. Este hecho les proporciona una morfología muy similar a la de grandes núcleos carenados (Fig. 3: 5-6).

La mayoría de los núcleos presentan una tabla única, que se desarrolla de forma paralela al eje longitudinal del soporte empleado, sobre su cara más ancha. Esto podria indicar la búsqueda de soportes lo más largos posible (en función de las limitaciones impuestas por las dimensiones de la materia prima) y proporcionalmente anchos. El estudio de las dimensiones medias de los negativos de las extracciones mayores en los núcleos estudiados dan como resultado $24,5 \mathrm{~mm}$, con un valor máximo de $41 \mathrm{~mm}$ en el nivel 8 .

\section{- Fase de pleno débitage}

El débitage responde a una gestión unipolar, donde observamos dos tipos de soportes cuya morfología está en relación con la localización de los mismos en el núcleo. Ambos juegan papeles diferentes en la dinámica del débitage, aunque se interrelacionan. Se trata por un lado, de soportes de morfología rectilínea, que presentan una curvatura débil y los negativos de su cara dorsal paralelos, extraídos de la zona central de la tabla y que no cubren toda la longitud de la misma (Fig. 2: 7-9; Fig. 6: 26-27; Fig. 10). Por otro lado, soportes que presentan negativos convergentes y una cierta curvatura en su perfil (sobre todo en la parte distal), poseen en ocasiones un plano cortical lateral y son extraídos en el contacto entre la tabla y el flanco (Fig. 2: 1, 5-6, 10; Fig. 4). La función de este tipo de soportes es la de controlar el carenado y el cintrado del núcleo. Ésta puede ser completada (o reemplazada) por la creación de neocrestas o de semicrestas cuando la morfología del núcleo lo permite, por ejemplo cuando es cúbica (Fig. 2: 2-4), generando entonces un flanco casi perpendicular a la tabla. 

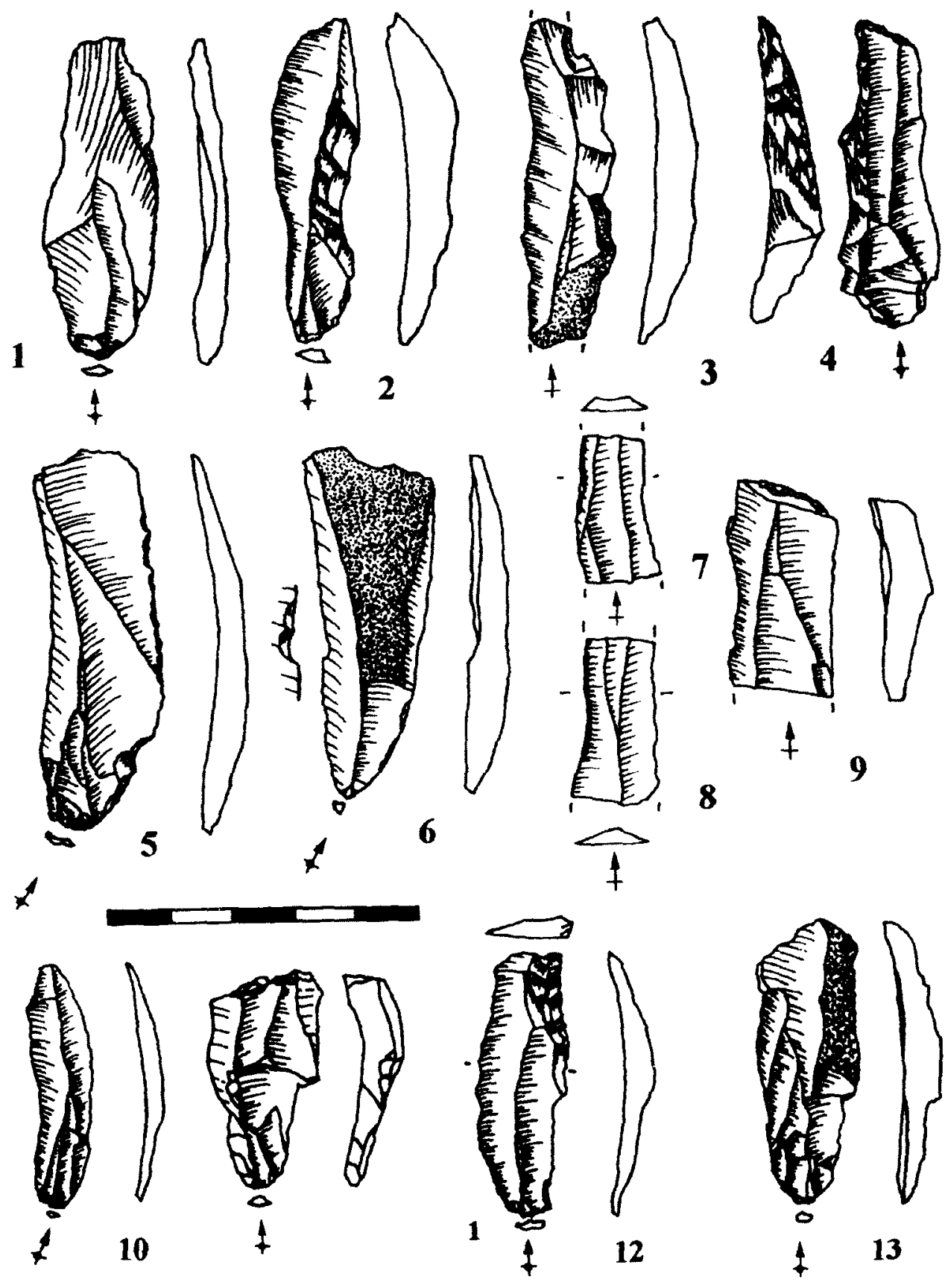

Fig. 2. Hojas del nivel 8. 1, 5, 6, 10-13 de extracción lateral; 2-4 neocrestas y 7-9 de débitage pleno (dibujos J. M. Maillo). 
La búsqueda de soportes rectilíneos es visible en las tablas de los núcleos de esta categoría. Asi, en ciertos casos, podemos observar una modalidad correspondiente a la intercalación de hojitas rectilíneas de pequeñas dimensiones entre otras de mayor tamaño. Este proceso de intercalación provoca en las hojitas de pequeñas dimensiones la acentuación de las características de regularidad y de rectitud en el perfil, teóricamente más variable en las de mayores dimensiones (Fig. 6: 3-5). Sin embargo, las hojas/hojitas de mayor tamaño no presentan tampoco una curvatura muy acusada. Esto puede ser debido a que en algunos núcleos se delimita su zona basal mediante grandes extracciones que impiden que exista dicha curvatura (Fig. 3: 1, 3)

La mayoría de los núcleos presenta una dinámica semienvolvente del débitage, pero existen algunos ejemplares en los que es envolvente. La bipolaridad es muy poco empleada y, cuando existe, se produce en el estadio final de la explotación de los núcleos (Fig. 3: 2).

En las dos modalidades, las cornisas de los núcleos presentan un frecuente trabajo de regularización y de reducción gracias a pequeñas extracciones o abrasión.

Los productos de acondicionamiento no se emplean únicamente para corregir el carenado o el cintrado de la tabla del núcleo, sino que gran número de ellos corrigen también la disposición de las nervaduras o reacondicionan la tabla tras un accidente de talla.

\section{- Fase de abandono}

Muchos de los núcleos presentan accidentes de talla graves o no presentan las condiciones morfotécnicas adecuadas para continuar el débitage (carenado y cintrado inadecuado), lo que le ha obligado a finalizar la producción en ellos. Sin embargo, existen otros aparentemente "aptos" en los que también se detuvo la producción. Este hecho nos sugiere que la detención de la producción puede estar ligada en parte a aspectos económicos. Tal vez una talla menor de los soportes no es útil para el grupo paleolítico.

\subsection{Esquema II: Los núcleos carenados}

Son muy numerosos los trabajos consagrados a la descripción de los aspectos cuantitativos y cualitativos de la producción de hojitas según este método de explotación, tanto a partir de la observación del material arqueológico (Lucas, 1997; 2001; Chiotti, 1999; Bon, 2000; Chazan, 2001, Le Brun-Ricalens \& Brou, 2003) como experimentalmente (Soriano, 1998; Lucas, 2000; Chiotti, 1999; Hays \& Lucas, 2001).

- Fase de mise en forme

Los núcleos carenados (52 ejemplares en el nivel 8 y 11 en el 9) están realizados a partir de lascas o de tectoclastos ( 28 en el nivel 8 y 8 en el nivel 9 ), pero 

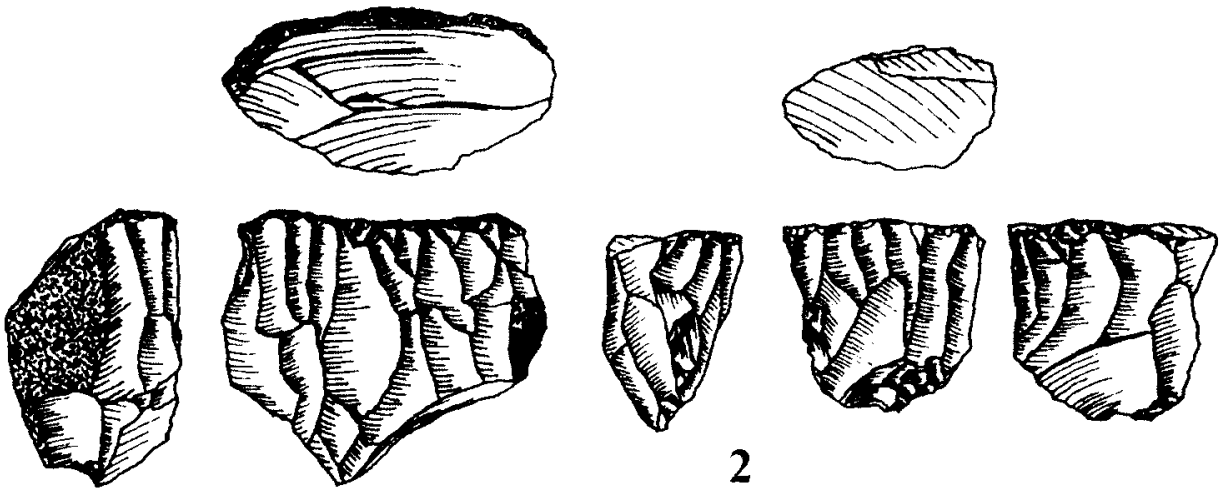

2
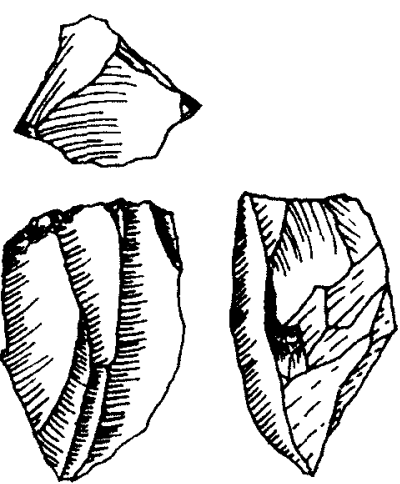

4

3
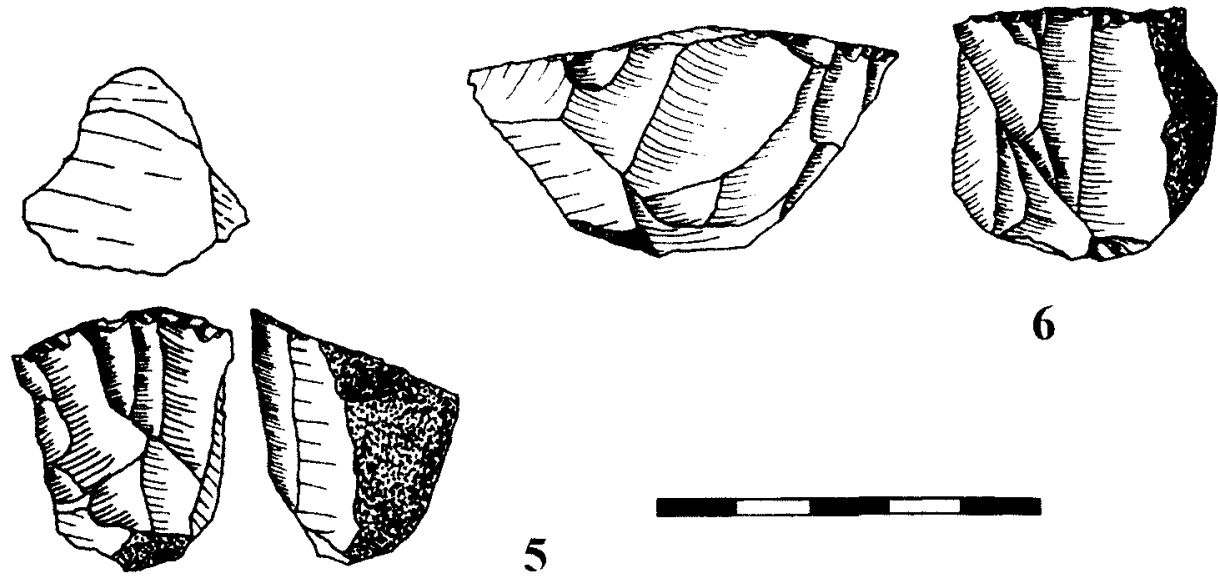

6

5

Fig. 3. Núcleos prismáticos de hojas/hojitas del nivel 8 , todos sobre silex (dibujos de J. M Maillo). 

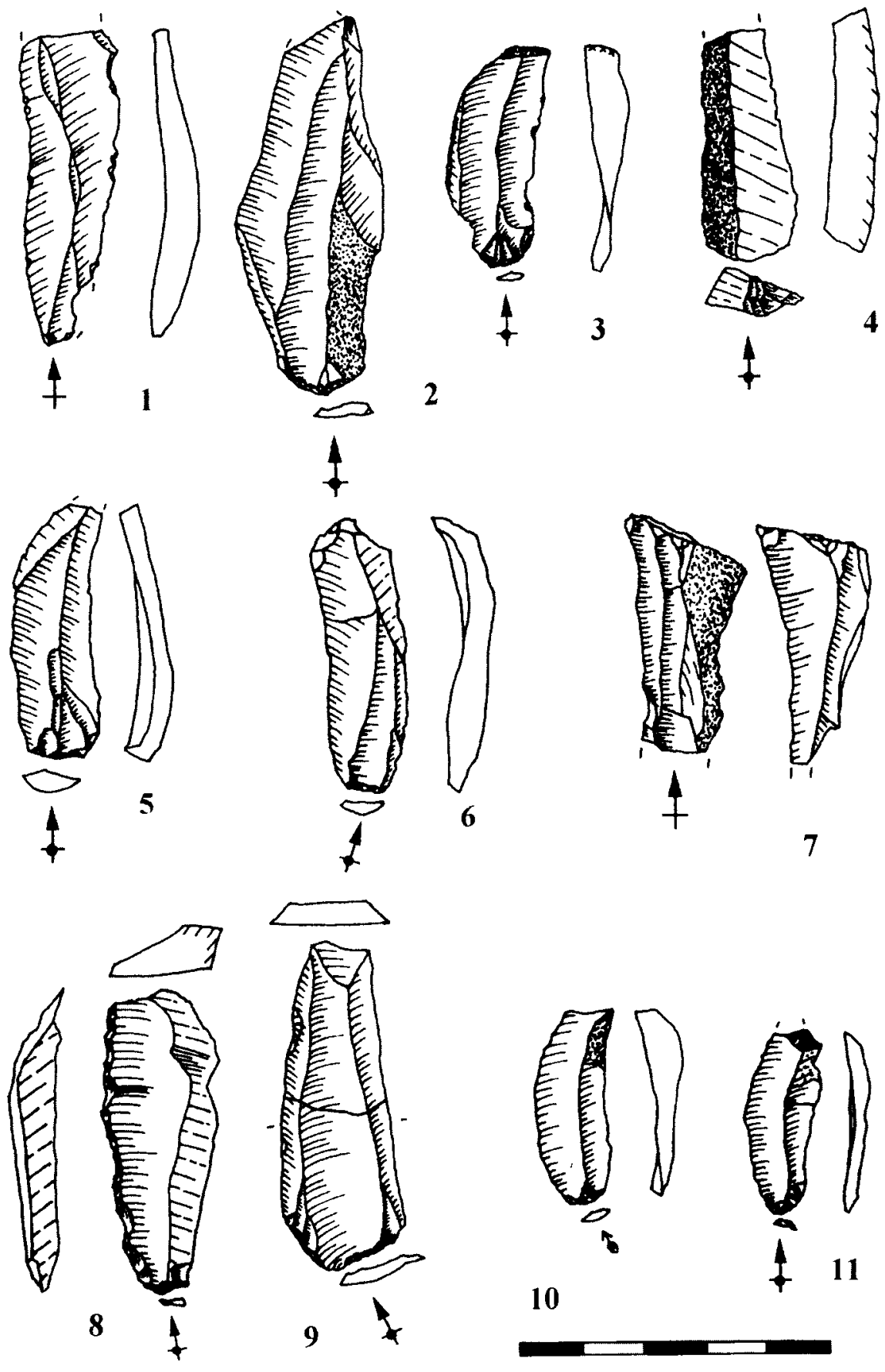

Fig. 4. Hojas de extracción lateral del nivel 9 (dibujos de J. M. Maillo). 
los encontramos también, de forma marginal, sobre plaqueta o sobre hoja. En todos los casos existe una adecuación morfométrica entre el soporte y el tipo de explotación que va a ser efectuada. Cuando el soporte es una lasca o una hoja, la cara bulbar es empleada como plano de percusión y la tabla de extracción se desarrolla en el extremo distal o sobre uno de los lados (Fig. 5). En los tectoclastos la relación entre el plano de percusión y la tabla está condicionada por las caracteristicas naturales de la pieza.

La relación entre los flancos y la tabla permite iniciar la explotación. Una muesca o una cresta lateral crean una nervadura a partir de la cual la extracción de las hojitas se puede desarrollar. Tras este tipo de preparación, la tabla adopta una morfología rectangular o triangular, generalmente desviada hacia el lado en el que se encuentra la muesca o la cresta. La tabla es sensiblemente oblicua en relación con el plano de percusión.
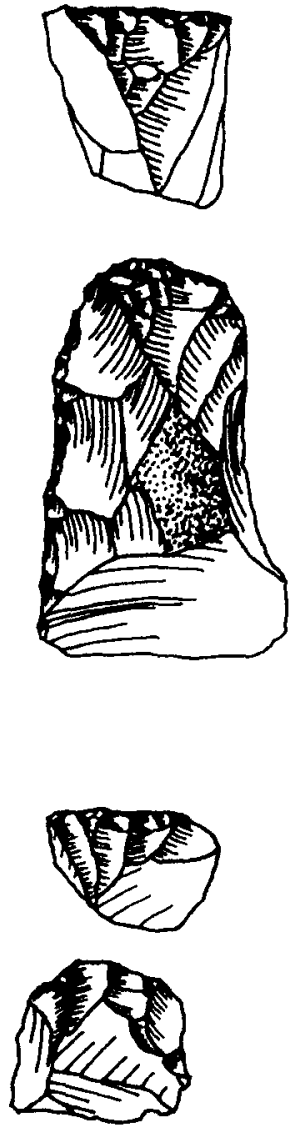
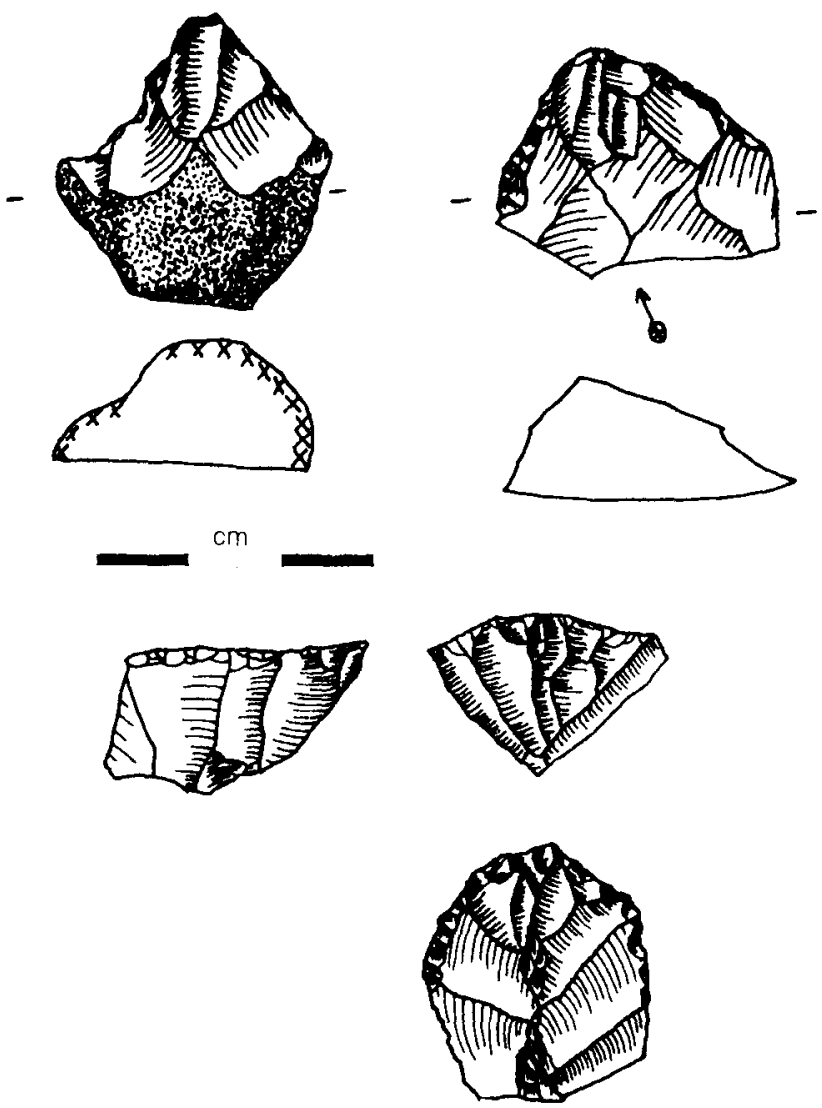

Fig. 5. Núcleos/raspadores carenados del nivel 8 (dibujos J. M. Maillo). 


\section{- Fase de pleno débitage}

El débitage es concebido de manera unipolar. Este tipo de explotación necesita un reacondicionamiento frecuente de la nervadura que encuadra la tabla gracias a las lascas de acondicionamiento que reacondicionan el cintrado. Numerosas lascas de este tipo han sido reconocidas en el transcurso del estudio de la colección. En un solo caso, el carenado es también controlado por medio de una cresta distal (modalidad ésta ampliamente conocida en otras colecciones como la de Tuto de Camalhot; Bon, 2000), como se puede apreciar en la figura 5. En ocasiones, la rectificación del carenado y del cintrado de la tabla es realizada por medio de neocrestas distales cuyos negativos de preparación son muy pequeños y no dejan huella sobre el núcleo-raspador (Fig. 6: 17-19).

Las hojitas con torsión son típicas de este tipo de explotación. Resultan de la extracción de soportes a lo largo de las nervaduras generadas por el contacto entre la tabla y los negativos de las muescas laterales de acondicionamiento. Este hecho les hace propicios para la producción de hojitas tipo Roc-de-Combe, que no son muy numerosas en nuestra serie (sólo 8 hojitas retocadas son de este tipo en el nivel 8 y ninguna en el 9), mientras que entre los soportes brutos son 67 en el nivel 8 . En todo caso, su proporción es muy débil en relación con el número total de hojitas que contiene el nivel.

La mayoría de las hojitas extraídas presentan, como ya se ha comentado anteriormente, un perfil curvo, siendo la torsión menos característica. Los soportes que poseen estas características pueden haber sido realizados a partir de raspadores carenados cuyas extracciones son realizadas en el centro de la tabla y no en el lateral, en contacto con el borde. Este hecho ha sido ya constatado en numerosas ocasiones, tanto arqueológica (Bon, 2000) como experimentalmente (Lucas, 1999). La regularidad y la anchura de los soportes podrían esta en relación con el tamaño de la tabla, en la colección en estudio, de un tamaño apreciable.

\section{- Fase de abandono}

Es difícil de apreciar los grados de agotamiento en los raspadores carenados debido a la heterogeneidad de sus medidas. Pero la mayoría presentan accidentes de talla que impiden la continuidad del débitage, sobretodo reflejados (Fig. 6).

Pese a su número elevado, su lugar en la producción de hojitas no es muy importante, no solamente en lo que concierne a las hojitas retocadas, sino también a las brutas. Si no fuese así encontraríamos mayor número de hojitas características de este esquema de explotación (Fig. 6: 12-14). 

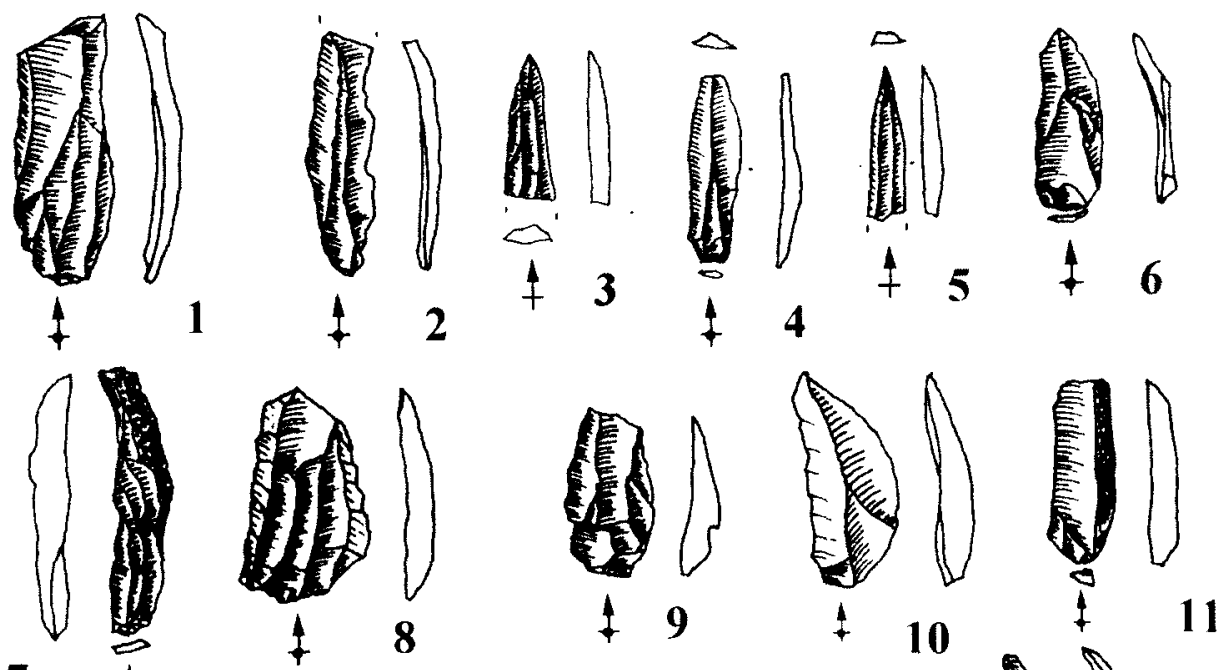

7 f
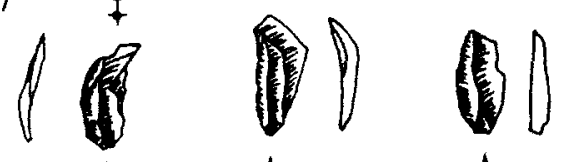

121
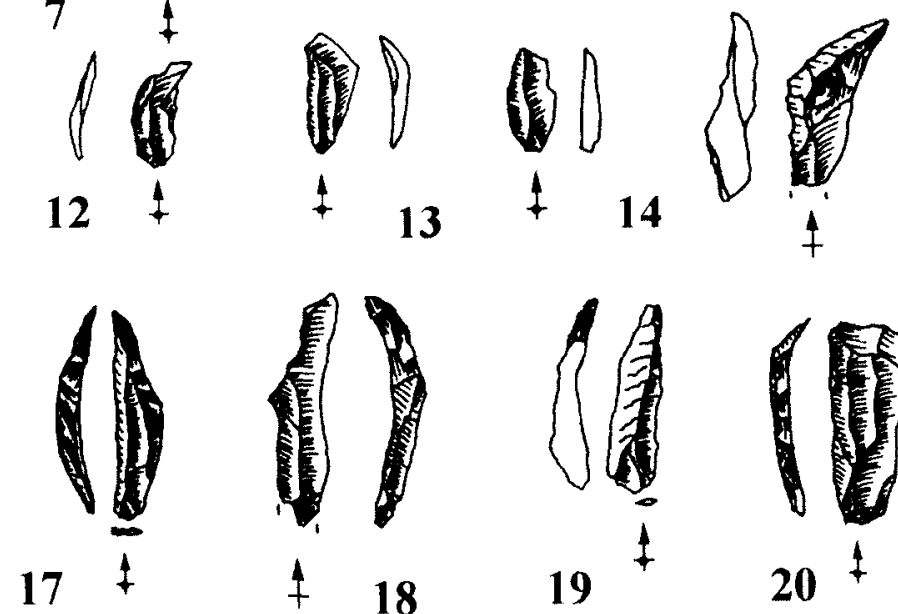

$7 \quad 18$
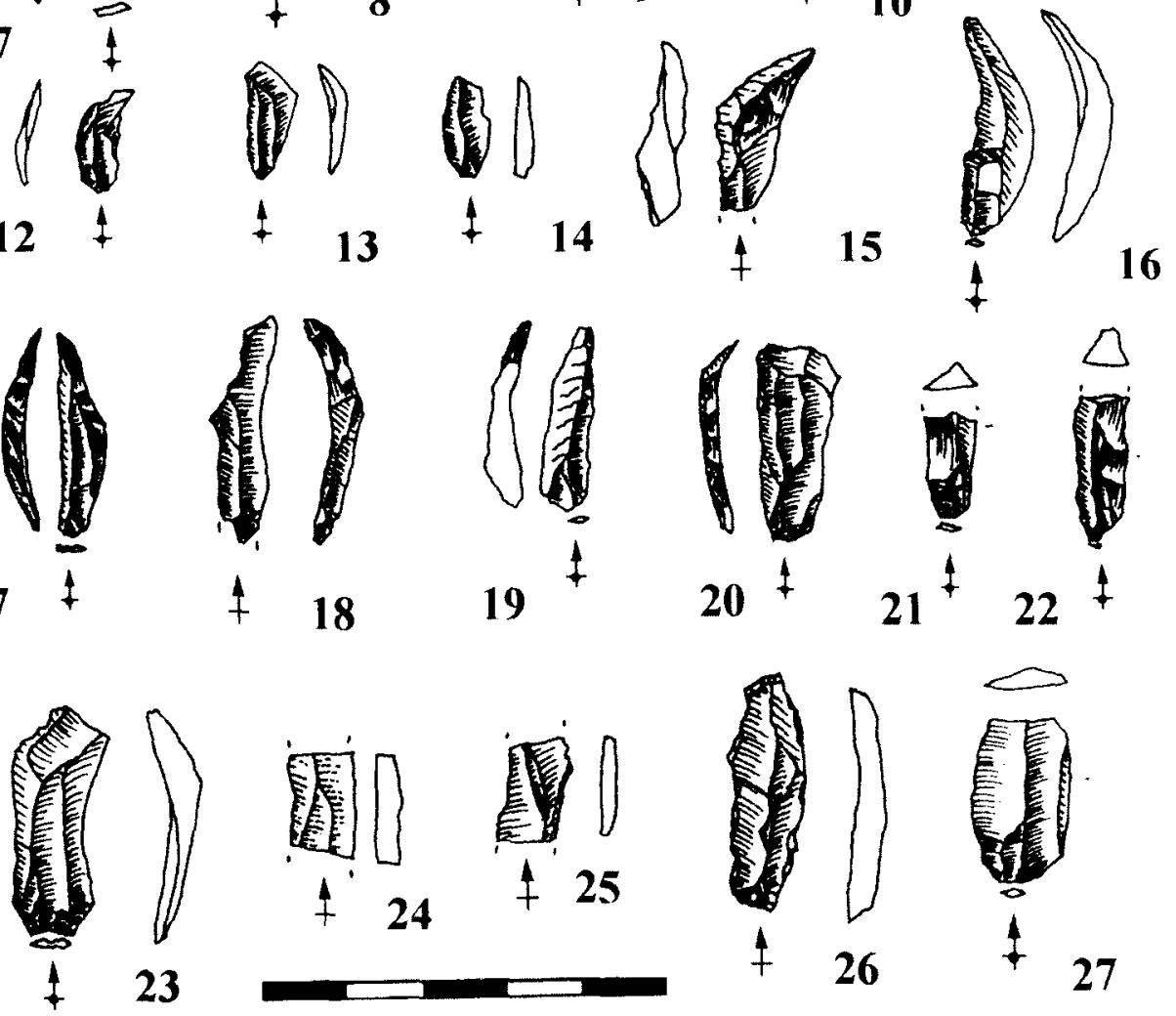

Fig. 6. Hojitas del nivel 8, todas en sílex excepto. 24, cuarcita; 25-26, cristal de roca; 27 , oligisto (dibujos de J. M. Maillo). 


\subsection{El papel de los buriles en la producción de hojitas}

Los buriles no tienen un papel importante en la producción de hojitas de estos niveles. Ninguno de ellos pertenece a las categorías comúnmente aceptadas como posibles núcleos de hojitas (busqués y carenados). Observando el número de extracciones que poseen, constatamos que, en el nivel 8 , solamente $2 / 3$ poseen una o dos extracciones (hecho que corroboran también los golpes de buril, donde la mayoría son de primer y segundo orden). En cuanto a su longitud, corresponderían a hojitas de dimensiones pequeñas $(19,9 \mathrm{~mm}$ de media). Por tanto, examinando la morfología de estas extracciones sobre los buriles, y su escasa recurrencia, así como la preparación sumaria de los planos de percusión, preferimos no incluir estas piezas dentro de la producción de hojitas.

\subsection{Síntesis}

Recapitulando, la producción de hojas/hojitas del Auriñaciense arcaico de Cueva Morín está caracterizada por los aspectos siguientes (Fig. 10):

a) Existe un continuum entre la producción de hojas y de hojitas.

b) El método de explotación más empleado es a partir de núcleos prismáticos por medio de una gestión unipolar.

c) La mise en forme es simple, existe una adecuación morfométrica previa del volumen. El inicio del débitage comienza gracias a hojas de entame que abren la superficie de explotación o tabla. Los planos de percusión son preparados y reavivados durante el proceso de débitage por medio de la extracción de tabletas de núcleo.

d) Dos tipos de soportes son obtenidos: 1) hojitas de perfil rectilíneo que presentan una buena regularidad y que serían obtenidas en el centro de la tabla; 2 ) las hojitas de perfil más curvo, sobretodo en la parte distal, con cortex lateral (que puede ser sustituido por neocrestas), serian obtenidas en la intersección entre la tabla y el flanco. Estas extracciones tienen como objetivo controlar el cintrado de la tabla y permite obtener las condiciones volumétricas del núcleo para generar el primer tipo de soportes.

e) Las hojitas son empleadas para realizar hojitas Dufour, subtipo Dufour. Las hojas presentan una mayor diversidad tipológica.

\section{LA PRODUCCIÓN DE LASCAS}

Las lascas son muy numerosas en el componente lítico del Auriñaciense arcaico de Cueva Morín. Están son 660 lascas brutas y 131 retocadas en el nivel 9 y 768 brutas y 234 retocadas en el nivel 8 . Aunque algunas de ellas proceden de la 
mise en forme de los núcleos de hojas, la mayoría responden a concepciones discoides del débitage. En cuanto a los núcleos, disponemos de 14 ejemplares para el nivel 9 y 3 para el nivel 8 (Figs. 7, 8 y 9).

Las materias primas son muy diversas destacando la arenisca y ofita, ya que este método es el exclusivo para tallar estas materias primas. Además, también encontramos este tipo de producción en la cuarcita, la caliza y el silex. Los soportes son cantos o plaquetas. Sólo en algún caso se emplean lascas, en este caso la superficie de explotación es la cara bulbar.
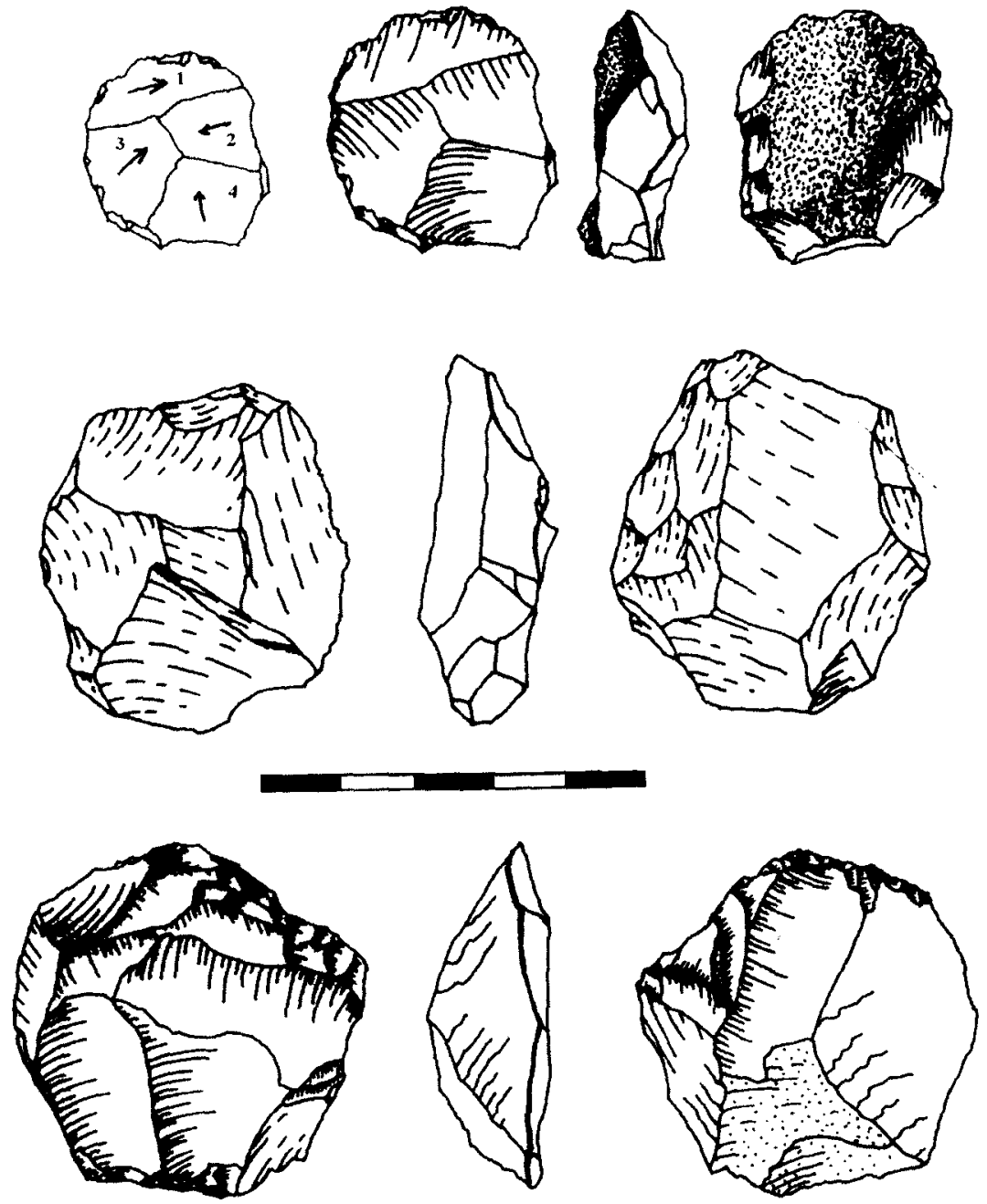

Fig. 7. Núcleos discoides unifaciales del nivel 9 (dibujos de J. M. Maillo), 


\section{- Fase de mise en forme}

Todos los núcleos discoides se han explotado a partir de métodos unifaciales, es decir, la explotación se efectúa en una sola superficie de explotación. Los núcleos son, por tanto jerarquizados: una superficie actúa como plano de percusión y la otra como plano de explotación.

El plano de explotación se confecciona mediante una serie de extracciones secantes no invasivas alrededor de todo el perímetro del núcleo. Cuando las condiciones angulares son las adecuadas se deja la superficie natural del núcleo.

No existe un descortezado previo del núcleo, por lo que los primeros productos de la explotación discoide presentarán la superficie dorsal con cortex parcial o total.

\section{- Fase de explotación}

Los soportes obtenidos a partir de este esquema de producción son los ya repetidamente descritos en numerosos lugares (Boëda, 1988, 1993, 1994, 1995). Dos son las direcciones de débitage que podemos observar es este tipo de explotaciones: centrípeta y cordal. Ambas mantienen una relación paradójica, ya que los soportes de dirección centrípeta eliminan la convexidad necesaria en este tipo de explotaciones, mientras que las de dirección cordal la reaviva.

Son típicos de la dirección centrípeta las lascas más anchas que largas y las cuadradas. Por su parte, las de dirección cordal las componen las puntas pseudolevallois, las lascas desbordantes y las lascas desbordantes de dorso limitado (Meignen, 1993) muy comunes en nuestro conjunto. No suelen presentar preparación en el anverso y cuando lo tienen ha sido realizado mediante pequeñas extracciones (Figs. 8 y 9 ).

En las fases finales la cumbre de la superficie de explotación del núcleo discoide ha descendido mucho debido a extracciones que sobrepasan dicha cumbre. Esto confiere a los núcleos una morfología similar a los Levallois recurrente centrípetos. (Slimak, 1998-1999; 2003; Terradas, 2003).

Debemos destacar que uno de los núcleos del nivel 9 presenta los negativos de extracciones que pueden denominarse como laminares. En este mismo núcleo la última extracción es bifacial (Fig. 7: 3).

\section{- Fase de abandono}

Básicamente, la finalización en la explotación de lascas es debido al agotamiento de los núcleos, así como a accidentes de talla como el reflejado de negativos. 


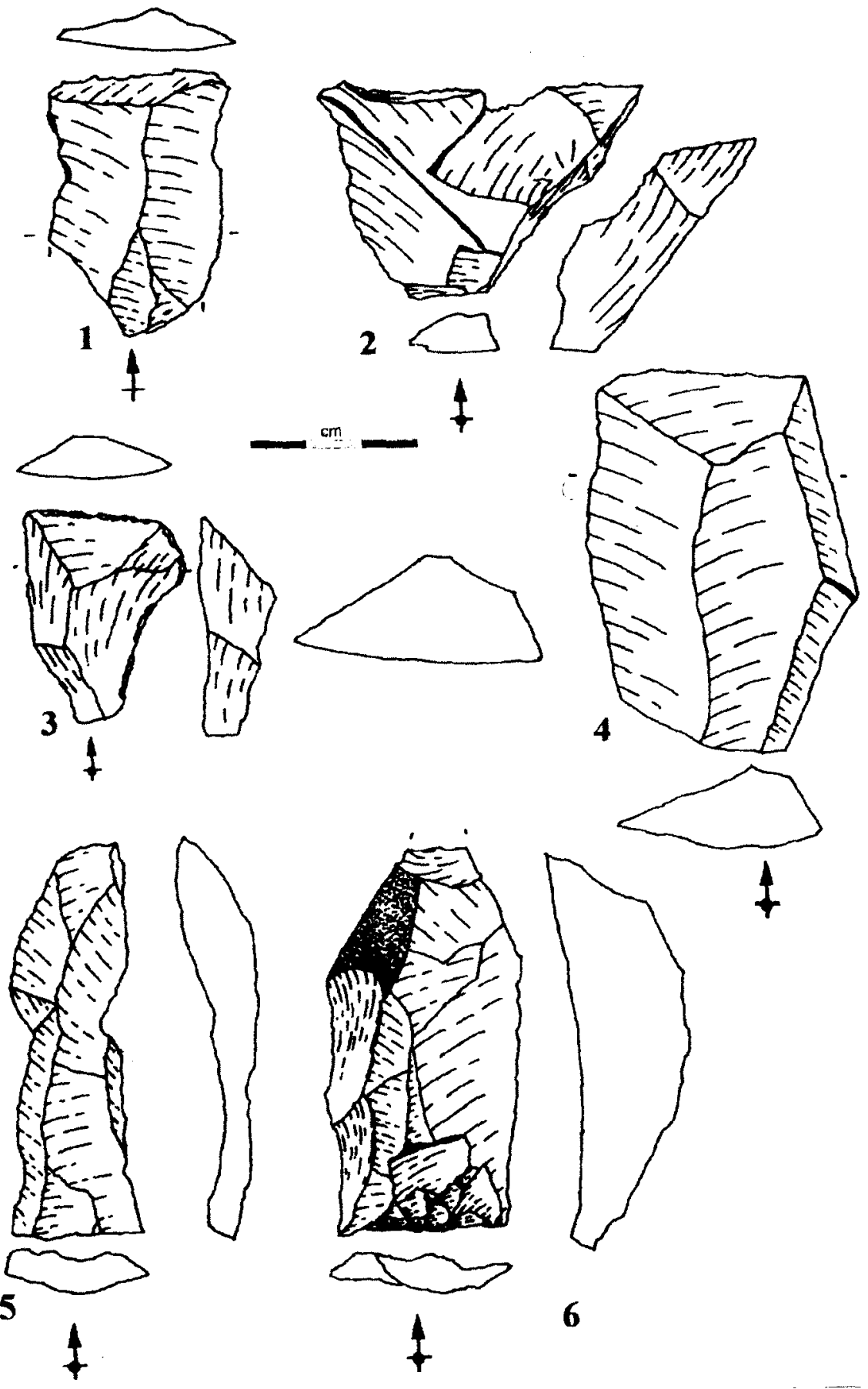

Fig. 8. Lascas de producción discoide en arenisca lofita del nivel 9 (dibujos de J. M. Maillo). 

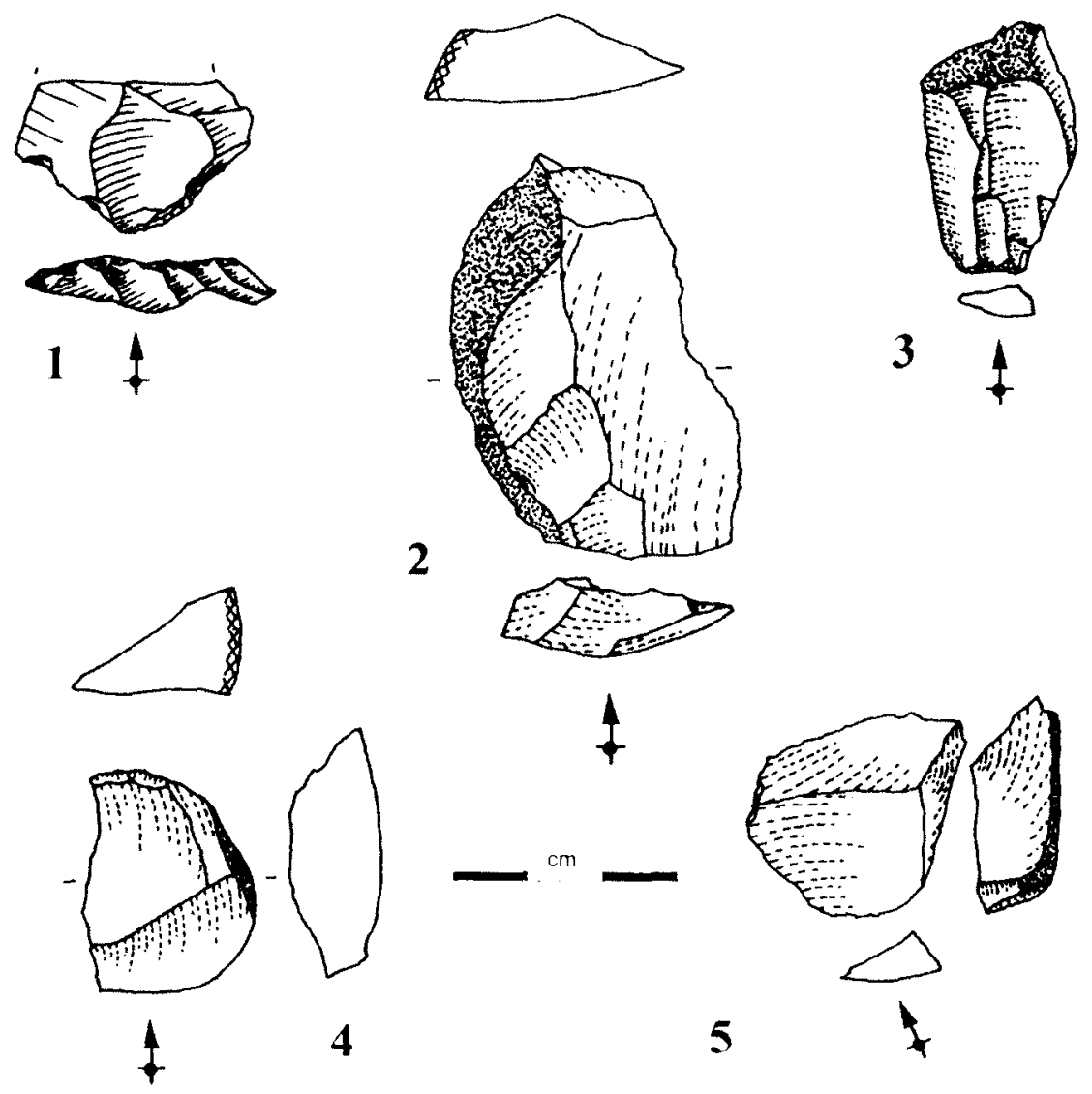

Fig. 9. Lascas de producción discoide del nivel 9. 1, silex; 2-5, cuarcita (dibujos de J. M. Maillo).

\subsection{Sintesis}

La producción de las lascas en el Auriñaciense arcaico de cueva Morín se puede caracterizar por las siguientes pautas:

a) La producción de lascas se produce bajo esquemas de débitage de concepción discoide.

b) El método discoide empleado es el unifacial. La mise en forme es simple con explotación en la superficie de explotación a partir de un plano de percusión periférico.

c) Los soportes obtenidos son los típicos de este tipo de explotaciones a partir de dos direcciones: cordal y centrípeta.

d) Los soportes son empleados para realizar piezas de sustrato en su gran mayoría (raederas, denticulados y muescas), aunque también raspadores, piezas de retoque lateral, etc. 


\section{OBJETIVOS DE LA PRODUCCIÓN}

La producción de soportes líticos presenta una diferenciación neta en cuanto al tipo de soporte deseado. Asi la producción de hojas y, sobre todo, de hojitas está confeccionada a partir de núcleos de morfología prismática y gestión unipolar (Fig. 10). Mientras, la producción de lascas se lleva a cabo a partir de concepciones discoides del débitage bajo el método unifacial.

\section{AURIÑACIENSE ARCAICO DE CUEVA MORÍN PRODUCCIÓN LAMINAR}
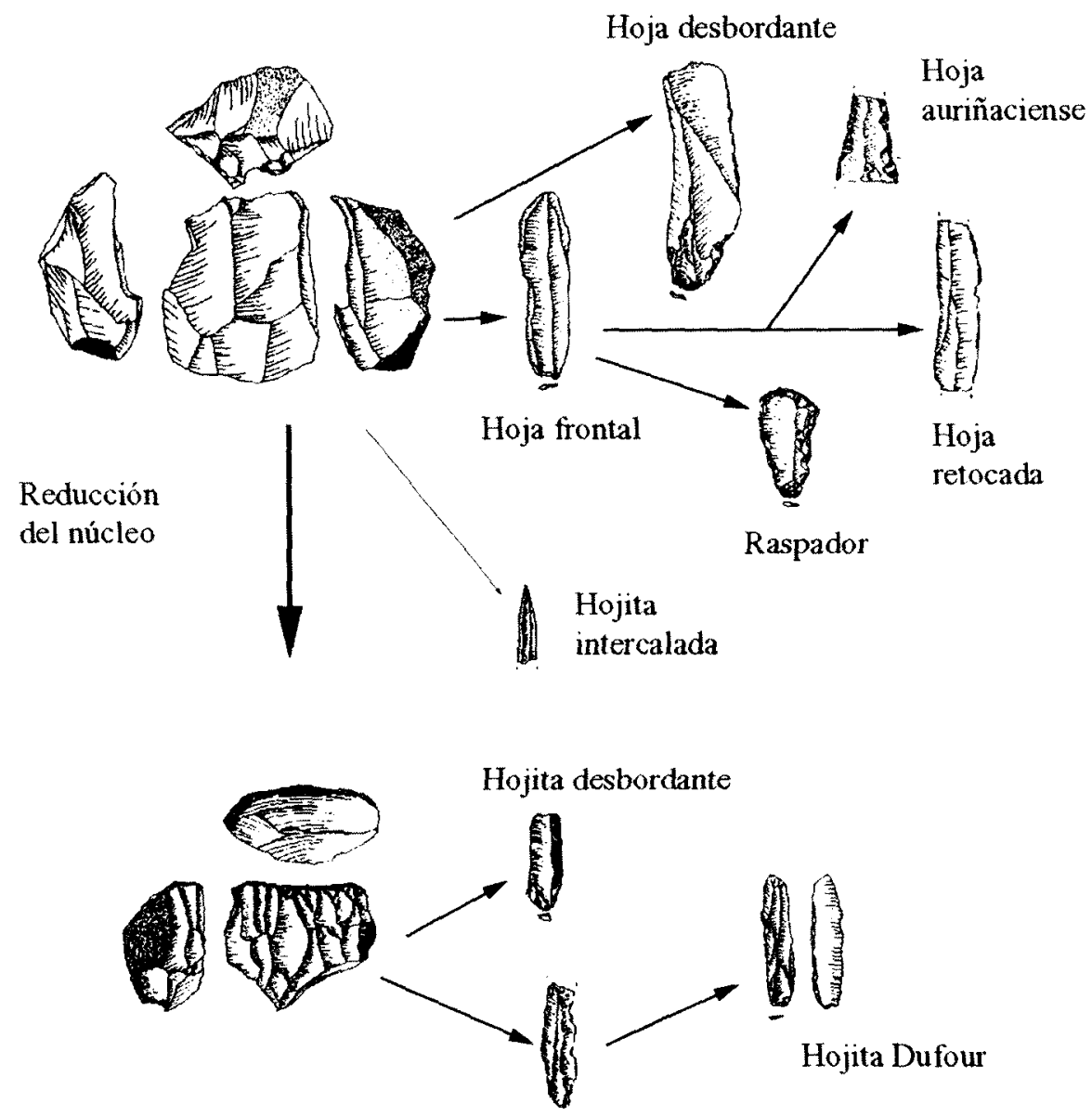

Hojita frontal

Fig. 10. Esquema sintético de la producción laminar del Aurinaciense arcaico de Cueva Morín. 
Junto con esta dicotomía en la producción de soportes, encontramos una convergencia en el uso de esos soportes dentro del conjunto retocado de ambos niveles. Parece obvia la búsqueda de hojitas en la producción laminar destinada, casi exclusivamente, a la confección de hojitas Dufour, subtipo Dufour (Fig. 11).
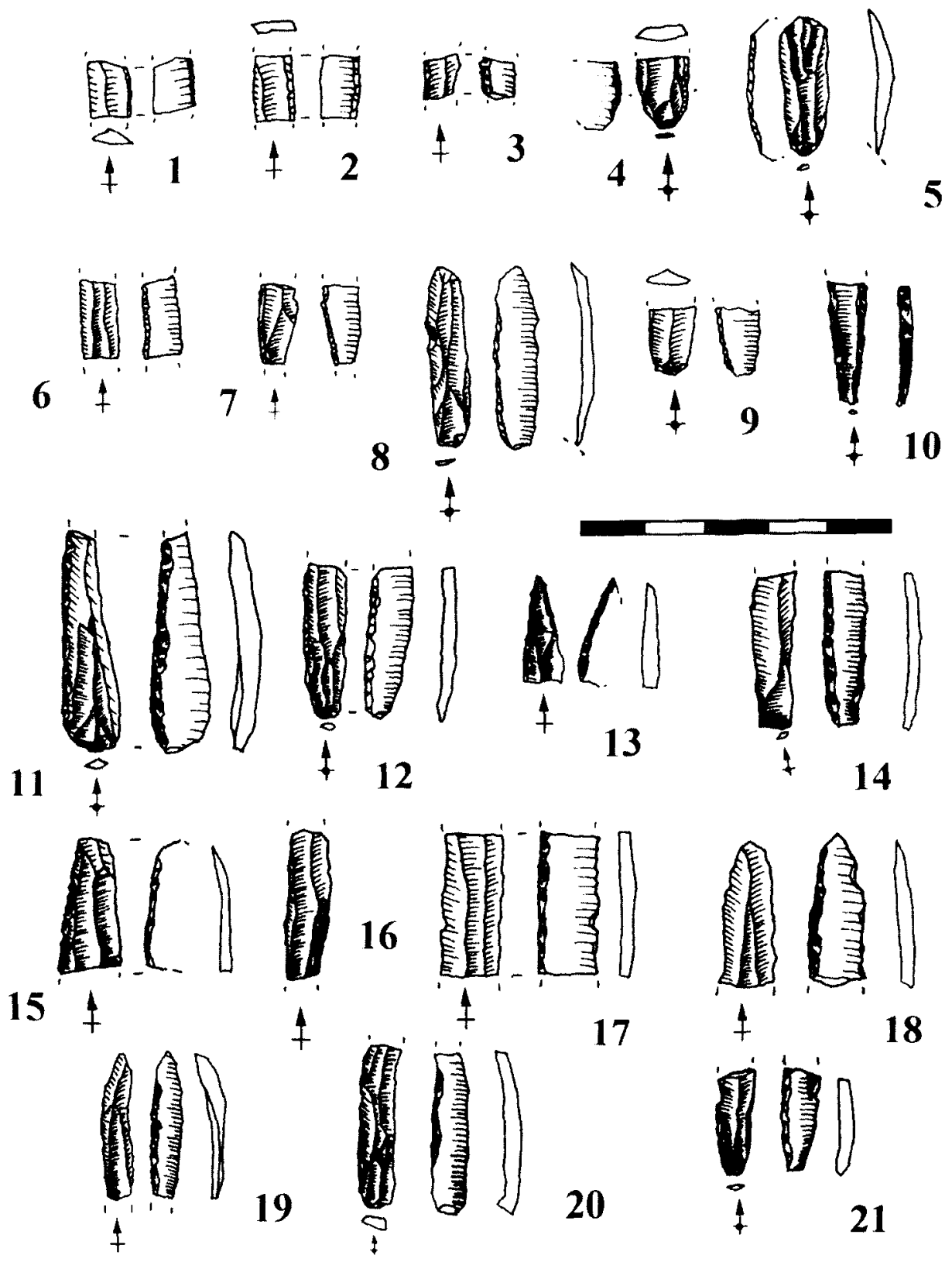

Fig. 11. Hojitas Dufour del nivel 8 de Cueva Morín (dibujos de J. M. Maillo). 
La producción de hojas es más variada, destacando en las piezas de retoque lateral y en buriles y raspadores (en estos últimos presenta proporciones similares a las de las lascas). Este hecho queda mejor reflejado en el nivel 8 , en donde la producción de hojas retocadas son más abundantes. El uso de hojitas de forma masiva en un solo tipo y la diversidad de categorías tipológicas confeccionadas a partir de las hojas refleja, desde nuestro punto de vista, un objetivo neto en la producción laminar: las hojitas.

Por otro lado, la producción de lascas está orientada a soportes no de igual longitud que las hojas, pero si más "masivos", es decir, son productos más espesos y anchos. Esta búsqueda de soportes espesos creemos está en relación con la función a la que se destinan dichos elementos. Además, destacamos que las lascas de explotación discoide en arenisca y ofita son de mucho mayor tamaño y no están retocadas, lo que suponemos forma parte del uso en estado bruto de las mismas.

\section{CUEVA MORÍN EN EL CONTEXTO CANTÁBRICO}

Existen muy pocas estratigrafías en la cornisa cantábrica en la que tengamos restos de los inicios del Paleolítico superior. Los yacimientos con niveles de ocupación que puedan ser adscritos con ciertas garantías a las primeras fases del Auriñaciense son Labeko Koba en el País Vasco (Arrizabalaga, 1995; Arrizabalaga \& Altuna, 2000), El Castillo en Cantabria (Cabrera et alii, este volumen) y La Viña en Asturias (Fortea, 1995; 1999). Existen otros yacimientos en donde las evidencias arqueológicas no permiten tener seguridad sobre su cronología: el nivel 8 de Otero (González Echegaray et alii, 1966) y El Pendo (González Echegaray, 1980) en Cantabria, Venta Laperra, Polvorín, Ekain, Lezetxiki (Arrizabalaga, 1995) o Antoliñako Koba (Aguirre, 2001) en el País Vasco.

El Auriñaciense en la región cantábrica comenzaba con el conjunto industrial que venimos denominando Auriñaciense arcaico y que en un primer momento fue dividido en dos facies, una denominada Pendo, sin hojitas Dufour y otra facies de tipo Morín en la que este morfotipo abundaba (Bernaldo de Quirós, 1982, 1994). A raíz de los nuevos hallazgos y conocimientos, asi como por el trabajo de campo realizado por nosotros, preferimos no considerar la facies Pendo debido a los problemas intrínsecos que plantea, tanto el yacimiento, como su colección (González Echegaray, 1980; Hoyos \& Laville, 1982).

Tanto desde un punto de vista tecnológico como tipológico existen similitudes entre los yacimientos de referencia dentro del marco metodológico aquí desarrollado: Castillo 16, Morín 9 y 8 y Labeko Koba VII. En Castillo (nivel 16) y Labeko Koba (nivel VII) existe la misma aplicación de métodos de débitage: producción de hojas/hojitas a partir de núcleos de morfología prismática y gestión unipolar, con un continuun entre la producción de hojas y de hojitas a partir de los mismos núcleos prismáticos mediante la reducción dimensional de los mismos. Los soportes obte- 
nidos son hojas rectilíneas sin torsión con la extracción de hojas desbordantes para mantener el cintrado de los núcleos. En todos ellos, las hojitas se presentan como el objetivo de la producción. Tipológicamente, las hojitas Dufour, subtipo Dufour son el elemento más característico de todos estos yacimientos. En este apartado podriamos catalogar también la industria del nivel XII de La Viña (Fortea, 1999), aunque con reservas dado lo preliminar de los resultados publicados. En el resto de categorías tipológicas no existe tanta unanimidad, por ejemplo, en Labeko Koba VII predominan los buriles y las piezas de sustrato son poco abundantes, al contrario de lo que ocurre en Morín 8 y 9.

Comparando el Auriñaciense arcaico de Morín con los yacimientos del Auriñaciense antiguo de Aquitania encontramos importantes diferencias. Las hojas pueden realizarse a partir de esquemas operativos similares. Sin embargo, la producción de hojitas es radicalmente diferente ya que se realizan a partir de núcleos carenados como ocurre en Brassempouy, Garet, Corbiac-Vignoble, Pataud, Hui, Toulousette o Barbas, aunque en este último también exista una explotación de hojitas a partir de núcleos prismáticos (Tixier \& Reduron, 1991; Ortega, 1998; Klaric, 1998; Chiotti, 1999; Bon, 2000; Le Brun-Ricalens, 1990, 1993). En ninguno de ellos existe un continuum entre la producción de hojas y de hojitas.

Por el contrario, el Auriñaciense arcaico de Morín presenta más similitudes con el Auriñaciense arcaico mediterráneo, Protoauriñaciense o Auriñaciense Inicial. Si comparamos nuestro yacimiento con yacimientos con Arcy-sur-Cure (Bon, 2000, Bon \& Bodu, 2002), o en el área mediterránea con L'Arbreda (Ortega et alii, en prensa), Esquicho Grapaou, La Laouza (Bazile et alii, 1981; Bazile \& Sicard, 1999), Riparo Mochi o Fumane (Bartolomei et alii, 1994; Broglio et alii, 1996; Khun \& Bietti, 2000, Kuhn \& Stiner, 1998) observamos que las similitudes son importantes. A nivel tecnológico, excepto en L'Arbreda, existe un continuum entre la producción de hojas y hojitas a partir de núcleos prismáticos de gestión unipolar, con hojas desbordantes para controlar el carenado del núcleo y una extracción de hojas rectilíneas en el centro de la tabla. Desde un punto de vista tipológico, observamos como las hojitas Dufour (subtipo Dufour) están ampliamente representadas.

En este mismo sentido se encontrarían los yacimientos de Gatzarria (Laplace, 1966; Saenz de Buruaga, 1991) y de Isturitz (Normand \& Turq, en prensa) en el País Vasco francés. El primero de ellos, Gatzarria (Laplace, 1966; Saenz de Buruaga, 1991), presenta dos niveles Protoauriñacienses (Cjn1 y Cjn2). Algunos investigadores han reclasificado al primero como perteneciente al Auriñaciense antiguo, mientras que el Cjn2 no sería clasificado como Protoauriñaciense ni tendria relación con los yacimientos de la región mediterránea. Se clasificaría, por tanto, como anterior al Auriñaciense antiguo (Bon, 2000). Esta interpretación se basa en los índices de raspadores carenados y hojas retocadas, así como en la morfología de las escasas láminas presentadas en las memorias originales. Desde nuestro punto de vista, este nivel presenta similitudes importantes con Labeko Koba VII 
como es el mayor porcentaje de buriles sobre raspadores. No debemos olvidar que en las series cantábricas resulta menos complicado ver similitudes diacrónicas en un mismo yacimiento que sincrónicas en varios yacimientos de la región (Arrizabalaga, 2000b). Por último, en base a los dibujos publicados del yacimiento (Laplace, 1966, Saenz de Buruaga, 1991) no creemos que exista base argumental suficiente como para decantarnos por una u otra clasificación, pero ésta no debe estar muy alejada del Auriñaciense arcaico cantábrico. El segundo de los yacimientos, Isturitz, presenta, en el nivel C4d, que es la base de la secuencia auriñaciense, una producción laminar basada en núcleos prismáticos con hojas/hojitas desbordantes y una gran importancia de las hojitas Dufour entre el conjunto retocado, como ocurre en Morín 8 y 9 . Posee además, para este nivel, dos dataciones de $34630 \pm 560$ (Gif 98237) y $36650 \pm 610$ (Gif 98238) que podría ubicar la base de la secuencia auriñaciense en momentos similares a los de Morín 8, 9 y La Viña XII. Sin embargo, la superficie excavada es aún demasiado pequeña como para aportar más seguridad a estas hipótesis, no descartándose, por parte de los responsables de la intervención, una cierta originalidad local en estos momentos (Normand \& Turq, en prensa).

Un elemento importante a la hora de clasificar las industrias del Auriñaciense es la industria ósea. Historiográficamente se asocia la azagaya de base hendida con el Auriñaciense antiguo o Auriñaciense I. Sin embargo, dicho tipo de azagaya aparece en numerosos yacimientos catalogados como Auriñaciense arcaico o Protoauriñaciense. Tal es el caso de L'Arbreda H o Fumane. En una situación similar, creemos, podría encontrarse la azagaya de base hendida hallada en el nivel XIII de La Viña (Fortea, 1999). Por lo que, pensamos, debemos relativizar la potencialidad cultural de este tipo.

Las dataciones para el Auriñaciense arcaico cantábrico no son muy numerosas. Tan sólo La Viña, Labeko Koba y Morín presentan dataciones de C14. Las de Labeko Koba sobre hueso y en el resto sobre carbón. En la década de los 70 se realizaron una serie de dataciones en Cueva Morín que aportaron datos sensiblemente incoherentes (Stuckenrath, 1978). Recientemente, unas nuevas dataciones aportan datos más precisos sobre la cronología del yacimiento y, concretamente, en torno a la cronología del Auriñaciense arcaico en la región (Maillo Fernández et alii, 2001). Como podemos comprobar en el cuadro 2, la nueva datación del nivel 8 de Cueva Morín es similar a la de La Viña XIII, lo que significa (si la industria de La Viña es Auriñaciense arcaico) que dicho complejo industrial se encuentra instalado plenamente en la región en torno al $36000 \mathrm{~B}$. P. lo que pone en relación directa a estos yacimientos con los de la vertiente mediterránea. Las dataciones obtenidas en Labeko Koba VII pueden reflejar el lapso temporal de este conjunto industrial en la región o bien que dichas dataciones presentan problemas tafonómicos (Arrizabalaga, 2000a). 
Cuadro 2. Dataciones de los yacimientos con Auriñaciense arcaico de la cornisa cantábrica.

\begin{tabular}{lccccc}
\hline Yacimiento & Nivel & Método & N. Lab. & Datación & Fuente \\
\hline La Viña & XIII & AMS & Ly-6390 & AMS-36500 +-750 & Fortea, 1999 \\
Morin & 8 & AMS & GifA-96263 & AMS-36590 +-1100 & Maillo et alii, 2001 \\
Labeko Koba & VII & AMS & Ua-3321 & AMS-31455 +-915 & Arrizabalaga, 2000 \\
\hline
\end{tabular}

\section{DISCUSIÓN}

El Auriñaciense arcaico identificado y descrito en Cueva Morín (niveles 9 y 8 ) presentan, desde un punto de vista tecnológico, una similitud muy estrecha con otros conjuntos regionales como Labeko Koba VII o Castillo 16. Tipológicamente estos conjuntos, pese a cierta variabilidad interna, presentan elementos comunes como es la gran importancia del utillaje microlaminar, sobre todo las hojitas Dufour, subtipo Dufour. En este ámbito podríamos abarcar también los primeros niveles Auriñacienses de La Viña. Cronológicamente, tanto Cueva Morín, como La Viña presentan dataciones similares, en torno al 36500 B.P.

Estos elementos tecnológicos y tipológicos ponen en relación tanto a Cueva Morín como al resto de los conjuntos del Auriñaciense arcaico o Protoauriñaciense (sensu Laplace) con los yacimientos de ámbito mediterráneo como L'Arbreda, La Laouza, Esquicho-Grapaou, Fumane, Riparo Mochi o Arcy-sur-Cure, este último fuera de dicho ámbito geográfico. Esta relación cantábrico-mediterránea acentúa la dicotomía existente entre el Protoauriñaciense y el Auriñaciense antiguo aquitano tanto a nivel geográfico como tecnológico (Bon, 2000, 2002). Este panorama sobre el inicio del Auriñaciense se ve reforzado por una mayor antigüedad del Auriñaciense arcaico frente al Auriñaciense antiguo: yacimientos como Fumane o L'Arbreda presentan dataciones comprendidas entre 42000 y 36000 B.P, mientras que la datación más antigua correspondiente al Auriñaciense antiguo corresponde a Castanet, nivel de base, con $35200 \pm 1100$ (Pelegrin \& O'Farrell, 2001).

Quedaría por resolver la vía de comunicación entre el Auriñaciense arcaico cantábrico y mediterráneo. Dos son las vías posibles: 1) Por el norte de los Pirineos ○ 2) a través de la cuenca del río Ebro. En ninguna de las dos encontramos evidencias que nos hagan pensar en una posible comunicación. La cuenca del Ebro adolece de una prospección sistemática a la que si ha sido sometida la región norte de los Pirineos. Por ahora, los únicos yacimientos que podrian estar en relación con el Auriñaciense arcaico cantábrico son Gatzarria e Isturitz presentan aun datos poco esclarecedores, de los que el último de ellos, Isturitz, presenta sílex procedente de la cuenca del Ebro (Normand \& Turq, en prensa). Aunque debemos atender también al papel de yacimientos como Dufour o Piage, actualmente en revisión. 
El papel de los elementos denominados arcaicos o de sustrato en las colecciones líticas del Auriñaciense cantábrico resulta uno de los mayores elementos de identificación del mismo. Como hemos comprobado, los esquemas de producción de lascas en Cueva Morín a partir de esquemas de concepción discoide resultan muy importantes no sólo a lo largo de los dos niveles pertenecientes al Auriñaciense arcaico, sino también en el Chatelperroniense del nivel 10. Este hecho está también constatado en Castillo 16, Labeko Koba VII o Gatzarria Cjn2. La aparición, sobre todo en Cueva Morín, de débitage discoide, junto a numerosas piezas de sustrato (raederas, denticulados y muescas) nos debe hacer reflexionar sobre el peso de la herencia de las tradiciones tecnológicas anteriores. Bien es cierto, que el estudio del débitage de lascas es uno de los grandes olvidados en los estudios del Paleolítico Superior (Bracco, 1999). En Cueva Morín, este tipo de explotación en proporciones tan grandes y en todo tipo de materias primas presenta una realidad que permite poner en relación estos conjuntos industriales con los anteriores (Chatelperroniense o incluso Musteriense Final).

Por último, a partir de la identificación y caracterización tecnológica de los inicios del Auriñaciense en la región cantábrica, creemos que es más conveniente mantener la denominación de Auriñaciense arcaico, no sólo para los yacimientos de la cornisa cantábrica, sino para aquellos de ámbito mediterráneo. Esto es así porque pensamos que el término Protoauriñaciense presenta unas connotaciones interpretativas importantes de las que no debe, aunque así haya sido de facto, ser despojado.

\section{BIBLIOGRAFIA}

Aguirre, M. (2001): Antoliñako Koba. IV Campaña. Arkeoikuska, 00: 64-65.

ALtunA, J. (1971): "Los mamíferos del yacimiento prehistórico de Morin". En González Echegaray, J. \& Freeman, L.G. (eds.): Cueva Morín. Publicaciones del Patronato de las cuevas prehistóricas de la provincia de Santander, VI, pp. 369-398.

Arrizabalaga, A. (1995): La industria lítica del Paleolítico Superior Inicial en el Oriente Cantábrico. Tesis Doctoral. Univ. Pais Vasco, pág.1000.

- (2000a): "El yacimiento arqueológico de Labeko Koba (Arrasate, País Vasco)». Entorno. Crónica de las investigaciones. Estratigrafia y estructuras. Cronologia absoluta. En Arrizabalaga, A. \& Altuna, J. (eds.): Labeko Koba (Pais Vasco). Hienas y Humanos en los albores del Paleolítico Superior. Munibe, 52: 15-72.

- (2000b): "Los tecnocomplejos líticos del yacimiento arqueológico de Labeko Koba (Arrasate, Pais Vasco)». En Arrizabalaga \& Altuna (eds.): Labeko Koba (Pais Vasco). Hienas y Humanos en los albores del Paleolitico superior. Munibe, 52: 193-343.

Arrizabalaga, A. \& Altuna, J. (2000): Labeko Koba (Pais Vasco). Hienas y Humanos en los albores del Paleolítico Superior. Munibe, 52, San Sebastián, 395 pág.

Bartolomel, G.; Broglio, A.; Cassoli, P. F.; Castelleti, L.; Cattani, L.; Cremaschi, M. Giacobini, G.; Malerba, G.; Maspero, A.; Peresani, M.; Sartorelli, A. \& Tagliacozzo. (1994): "La Grotte de Fumane. Un site aurignacien au pied des Alpes». Preistoria Alpina, 28, pp. 131-179.

Bazile, F.; Bazile-Robert, E.; Brugal, J-Ph.; Duindiand, F.; Gulllerault, Ph.; Renault-Miskovsky, J. \& RoGER, L. (1981): “L'abri sous roche de La Laouza». Études Quaternaires Languedociennes, Mémoire 1, pág. 104.

BAZILE, F. \& SICARD, S. (1999): "Le prémier Aurignacien du Languedoc oriental dans son contexte méditerranéen». En Sacchi (ed.): Les facies leptolithiques du nord-ouest méditerranéen: milieux naturels et culturels. Mémoire de la Société Préhistorique Française, pp. 117-125. 
BERnALDo de Quirós, F. (1982): “Los Inicios del Paleolítico Superior». In Centro de Investigación y Museo de Altamira, 8, 347 pág.

BERNALDO DE QUIRÓS, F. (1994): "Las industrias del Paleolítico superior inicial cantábrico". In Bernaldo de Quirós, F. (ed): “El cuadro geocronológico del Paleolítico Superior Inicial». Monografías del Museo y Centro de Investigación de Altamira, 13: 213-223.

BOËDA, E. (1988): “Le concept Levallois et évaluation de son champ d'application». L'Homme de Néandertal, vol 4, pp. 13-26.

- (1993): "Le débitage Discoìde et le débitage Levallois récurrent centripète». B.S.P.F., 90, pp. 392-404

- (1994): Le concept Levallois: variabilité des méthodes. CNRS, Paris, pág. 280.

- (1995): "Caracteristiques techniques des chaines opératoires lithiques des niveaux micoquiens de Külna (Tchecoslovaquie)». Paléo, supl. 1, pp. 57-77.

BoN, F. (1998): «Réflexions sur les productions laminaires et lamellaires aurignaciennes à travers l'étude de quelques séries des Pyrénées française». En Project Collectif de Recherche: Comportements techniques et économiques des Sociétés au Paléolithique supérieur dans le contexte pyrénéen, $\mathrm{pp}$. 20-31.

- (2000): La Question de l'unité technique et economique de l'Aurignacien: Réflexions sur la variabilité des industries lithiques a partir de l'étude comparée de trois sites des Pyrénées Francaises. Thèse de Doctorat, Université Paris I, pág. 425.

- (2002): L'Aurignacien entre Mer et Océan. Réflexion sur l'unité des phases anciennes de l'Aurignacien dans le sud de la France. Société Préhistorique Française, Mémoire XXIX. 253 pág.

BON, F. \& Boou, P. (2002): «Analyse technologique du débitage Aurignacien». En Schmider, B. (dir.): L'Aurignacien de la Grotte du Renne, CNRS, Paris, pp.115-133.

BoRDES, J-G. (2002): Les interstratifications Châtelperronien/Aurignacien du Roc-de-Combe et du Piage (Lot, France). Analyse taphonomique des industries lithiques: implications archéoligiques. Tesis Doctoral. Université Bordeaux I. 365 pág. +2 anexos.

Bordes, J-G. \& LeNOBLE, A. (2002): "La "lamelle Caminade": un nouvel outil lithique aurignacien?». B.S.P.F., 99 (4): $735-749$.

Bracco, J.-P. (1999): "Le débitage d'éclats au Paléolithique Supérieur: quelques exemples, quelques réflexions". En Project Collectif de Recherche: Comportements techniques et économiques des Sociétés au Paléolithique supérieur dans le contexte pyrénéen, rapport, 1999, pp. 34-53.

Broglio, A.; Angelucci, D. E.; Peresani, M.; Lemorini, C. \& Rossetti, P. (1996): "L'industrie Protoaurignacienne de la Grotta di Fumane: Données preliminaires". En Actes du XIII Congres du UISPP, Forli, pp. 495-509.

Carballo, J. (1923): Excavaciones en la cueva del Rey, en Villanueva (Santanden). Junta Superior de Excavaciones y Antigüedades, 9, Madrid, pág. 40, IX lám.

Cendrero, O. (1915): Resumen de los bastones perforados de la Provincia de Santander. Comisión de Inves. Paleontológicas y Prehistóricas. Notas 1 y 2 . Madrid.

ChAZAN, M. (2001): “Bladelet production in the Aurignacian of La Ferrasie (Dordogne, France)». Lithic Technology, 26 (1): 16-28.

CHIOTTI, L. (1999): Les industries lithiques des niveaux aurignaciens de l'Abri Pataud, Les-Eyzies-de-Tayac (Dordogne): Etude technologique et typologique. Thèse de Doctorat. Museum National de Histoire Naturelie, pág. 839.

- (2000): «Lamelles Dufour et grattoirs aurignaciens (carénés et à museau) de la couche 8 de l'abri Pataud, Les Eyzies-de-Tayac, Dordogne'. L'Anthropologie, 104, Paris, pp. 239-263.

FORTEA, J. (1995): “Abrigo de la Viña. Informe y primera valoración de las campañas 1991-1994». Excavaciones Arqueológicas en Asturias, 1991-94, Oviedo, pp. 19-32.

FORTEA, J. (1999): “Abrigo de La Viña. Informe y primera valoración de las campañas de 1995 a 1998 ". Excavaciones Arqueológicas en Asturias, 1995-1998, Oviedo, pp. 31-41.

Gonzalez EChegaray, J. (1969): "El paso del Paleolitico Medio al Superior en la costa cantábrica». Anuario de Estudios Atlánticos, 15, Oviedo, pp. 273-279.

González Echegaray, J. (1971): “El paleolítico superior». En Gonzalez Echegaray, J. \& Freeman, L. G. (1971): Cueva Morín. Publicaciones del Patronato de las cuevas prehistóricas de la provincia de Santander, VI, Santander, pp. 190-297.

Gonzalez Echegaray, J. (1980): El yacimiento de la cueva de El Pendo. Excavaciones 1953-57. C.S.I.C. 270 pág.

Gonzalez Echegaray, J.; García Guinea, M. A. \& Begines, A. (1966): Cueva del Otero. Excavaciones Arqueológicas en España, 53. 85 pág., VIII láms.

Gonzalez Echegaray, J. \& Freeman, L. G. (1971): Cueva Morín. Publicaciones del Patronato de las cuevas prehistóricas de la provincia de Santander, VI, Santander, pág. 452. 
González Echegaray, J. \& Freeman, L. G. (1973) Cueva Morín. Publicaciones del Patronato de las cuevas prehistóricas de la provincia de Santander, X, Santander, pág.304.

- (1978): Vida y muerte en cueva Morin. Institución Cultural de Cantabria, Santander, pág. 357.

Hays, M. A. \& LuCAS, G. (2001): "Experimental Investigations of Aurignacian Dufour Bladelets". En Hays, M. A. \& Thacker, P. (eds): Questioning the Answers: re-solving Fundamental Problems of the Early Upper Paleolithic. British Archaeological Reports, 1005, pp, 109-116.

Hoyos, M. \& Laville, H. (1982): Nuevas aportaciones sobre la estratigrafía y sedimentología de los depósitos del paleolítico Superior de la Cueva de El Pendo (Santander): sus implicaciones. Zephyrus, XXXIV-XXXV: 285-293.

KLARIC, L. (1998): "Étude de l'industrie lithique du site de Garet (Landes)». En Cazals (coord): Project Collectif de Recherche: Comportements techniques et économiques des Sociétés au Paléolithique supérieur dans le contexte pyrénéen, pp. 32-41.

KuHN, S. L. \& STINER, M. (1998): “The Earliest Aurignacian of Riparo Mochi (Liguria, Italy)". Current Anthropology, $39 \$ 3$, pp. 175-189.

KUHN, S. L. \& BIETTI, A. (2000): «The Late Middle and Early Upper Paleolithic in Italy». En The Geography of Neanderthal and Moderns Humans in Europe and the Greater Mediterranean, pp. 49-76.

LAPLACE, G. (1966); “Les niveaux Casteperronien, Protoaurignacien ef Aurignaciens de la Grotte Gatzarria à Suhare en Pays Basque». Quatär, 17, pp. 117-140.

LAVILLE, H. \& HoYOS, M. (1994): “Algunas precisiones sobre la estratigrafía y sedimentología de cueva Morín (Santander)". En Bernaldo de Quirós, F. (ed): El cuadro geocronológico del Paleolítico Superior Inicial. Monografias del Museo y Centro de Investigación de Altamira, 13, Santander, pp. 200-209.

Le Brun-Ricalens, F. (1990): «L'occupation aurignacienne d'Hui (Bauville, Lot-et-Garonne). Présentation problématique et premiers résultats". B.S.P.F.,87 (9): 275-282.

LE BRUN-RICALENS, F. (1993): Réflexions préliminaires sur le comportement litho-technologique et l'occupation du territoire du Pays des serres à l'Aurignacian: Le gisement de "Touiousète" á Beauville (Lot-et Garonne), une occupation moustérienne et aurignacienne de plein air. Paléo, 5: 127-153.

LuCAS, G. (1997): "Les lamelles Dufour du Flageolet I (Bézenac, Dordogne) dans le contexte Aurignacien". Paléo, 9, Les Eyzies-de-Tayac, pp. 191-219

- (1999): “Production expérimentale de lamelles torses: approche préliminaire». B.S.P.F., 96 (2), pp. 145-151

- (2000): Les industries lithiques du Flageolet I (Dordogne), approche économique, technologique, fonctionnelle et analyse spatiale. Thèse de Doctorat. Université Bordeaux 1. 2 vols. pág. 307, pág. 295.

- (2001): "The Origin of Dufour Bladelet Torsion». En Hays, M. A. \& Thacker, P. (eds): Questioning the Answers: re-solving Fundamental Problems of the Early Upper Paleolithic. British Archaeological Reports, 1005, pp. 99-107.

Maillo Fernández, J. M.; Valladas, H.; Cabrera Valdés, V. \& Bernaldo de Quiros, F. (2001): "«Nuevas dataciones para el Paleolitico superior de Cueva Morín (Villanueva de Villaescusa, Cantabria)". Espacio, Tiempo y Forma, 14: 145-150.

MEIGNEN, L. (1993): L'abri des Canalettes: un habitat moustérien sur les Grands causses (Nant, Aveyron) Fouilles 1980-86. Monographie du Cra, 10, pág. 359.

Moure Romanillo, A. (1969-70): “Industrias auriñacienses y preauriñacienses en la Región Cantábrica españolas. Ampurias, 31-32, pp. 71-90.

NoRmand, CH. \& TURQ, A. (en prensa): “L'Aurignacien de la grotte d'lsturitz (France): la production lamellaire dans la séquence de la Salle de Saint-Martin". En Le-Brun, F. (ed): Productions lamellaires attribuées à L'Aurignacien: Chaînes opératoires et perspectives techno-culturelles.

ORTEGA, I. (1998a): “Présentation des productions laminaires et lamellaires aurignaciennes du niveau aurignacien de Barbas (Dordogne)". En Projet Collectif de Recherche: Comportements techniques et économiques des Sociétés au Paléolithique supérieur dans le contexte pyrénéen: 42-54.

Ortega I Cobos, D.; Soler, N. \& Maroto, J. (en prensa): "La production des lamelies pendant l'aurignacien archaiqque dans la grotte de l'Arbreda: organisation de la production, variabilité des méthodes et des objetifs". En Le-Brun, F. (ed): Productions lamellaires attribuées à L'Aurignacien: Chaînes opératoires et perspectives techno-culturelles.

Pelegain, J. \& O'Farrell, M. (2001): Sur la production lamellaire de l'abri Castanet (Dordogne, France). En Le Brun, F. (coord): Productions lameliaires atribuées à L'Aurignacien: Chaînes opératoires et perspectives techno-culturelles. XV Congrès de I'U.I.S.P.P. Preactas symposium 6.7.

Sáenz de Buruaga, A. (1991): El Paleolítico Superior de la Cueva de Gatzarria, Zuberoa, País Vasco. Anejos de Veleia, 6, pág. 426.

SChMider, B. \& Perpère, M. (1995): «Production et utilisation des lamelles dans l'Aurignacien de la Grotte du Renne, à Arcy-sur-Cure". En: Paléolithique supérieur et Epipaléolithique dans le nord-est de la France. Actes de la Table-Ronde de Dijon, pp. 4-10. 
Sımak, L. (1998-1999): La variabilité des débitages discoïdes au Paléolithique Moyen. Préhistoire Anthropologie Méditerranéennes, 7-8, 75-88.

- (2003): Les débitages discoïdes mousteriens: avaluation d'un concept technologique. En Peresani (ed.): Discoid Lithic Technology, B.A.R. International Series: 1120: 33-65.

SORIANO, S. (1998): «La production de lamelles torses dans les niveaux du Paléolithique supérieur ancien d'Umm El Tlel (Syrie). Exploration théorique et expérimentale de ses modalités". En: Préhistoire de Anatolie: Genèse de deux mondes. Actes du colloque international de Liège, 28 avril-3 mai, 1997, pp. $731-748$.

STUCKENRATH, R. (1978): “Dataciones de Carbono 14». En González Echegaray \& Freeman: Vida y muerte en Cueva Morín: pág. 215.

TeRRADAS, X. (2003): «Discoid flaking method: conception and technological variability». En Peresani. M. (ed.): Discoid Lithic Technology. Advances and implications. B.A.R. International Series, 1120.19-31.

TIXIER, J. \& REDURON, M. (1991): “Et passez au pays des silex: rapportez-nous des lames!» En 25 ans d'études technologiques en Préhistoire: Bilan et perspectives. Actes des rencontres, 18, 19 et 20 octobre 1990, pp. 235-243.

Vega del Sella, CondE dE LA (1921): El Paleolítico de Cueva Morín (Santander) y Notas para la climatología Cuaternaria. Comisión de Investigaciones Paleontológicas y Prehistóricas, Memoria 29, pág. 168. 